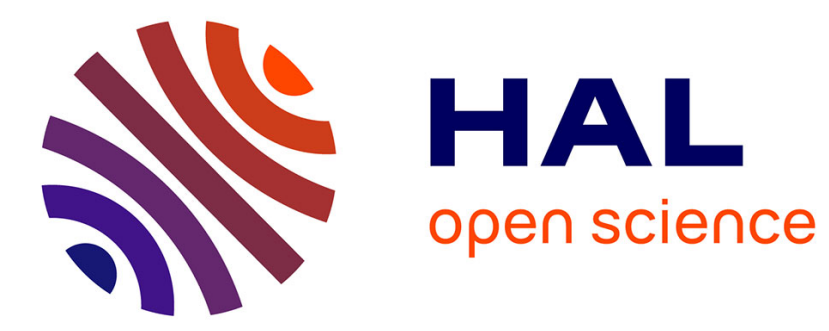

\title{
Equatorial mountain torques and cold surge preconditioning
}

\author{
Sylvain Mailler, François Lott
}

\section{To cite this version:}

Sylvain Mailler, François Lott. Equatorial mountain torques and cold surge preconditioning. Journal of the Atmospheric Sciences, 2010, 67 (6), pp.2101-2120. 10.1175/2010jas3382.1 . hal-01136866

\section{HAL Id: hal-01136866 https://hal.science/hal-01136866}

Submitted on 30 Mar 2015

HAL is a multi-disciplinary open access archive for the deposit and dissemination of scientific research documents, whether they are published or not. The documents may come from teaching and research institutions in France or abroad, or from public or private research centers.
L'archive ouverte pluridisciplinaire HAL, est destinée au dépôt et à la diffusion de documents scientifiques de niveau recherche, publiés ou non, émanant des établissements d'enseignement et de recherche français ou étrangers, des laboratoires publics ou privés. 


\title{
Equatorial Mountain Torques and Cold Surge Preconditioning
}

\author{
SYLVAIN MAILLER \\ Laboratoire de Météorologie Dynamique du CNRS, Paris, and École Nationale des Ponts et Chaussées, Marne la Vallée, France \\ FRANÇOIS LOTT \\ Laboratoire de Météorologie Dynamique du CNRS, Paris, France
}

(Manuscript received 17 November 2009, in final form 4 February 2010)

\begin{abstract}
The evolution of the two components of the equatorial mountain torque (EMT) applied by mountains on the atmosphere is analyzed in the NCEP reanalysis. A strong lagged relationship between the EMT component along the Greenwich axis $T_{M 1}$ and the EMT component along the $90^{\circ} \mathrm{E}$ axis $T_{M 2}$ is found, with a pronounced signal on $T_{M 1}$ followed by a signal of opposite sign on $T_{M 2}$. It is shown that this result holds for the major massifs (Antarctica, the Tibetan Plateau, the Rockies, and the Andes) if a suitable axis system is used for each of them. For the midlatitude mountains, this relationship is in part associated with the development of cold surges.

Following these results, two hypotheses are made: (i) the mountain forcing on the atmosphere is well measured by the regional EMTs and (ii) this forcing partly drives the cold surges. To support these, a purely dynamical linear model is proposed: it is written on the sphere, uses an $f$-plane quasigeostrophic approximation, and includes the mountain forcings. In this model, a positive (negative) peak in $T_{M 1}$ produced by a mountain massif in the Northern (Southern) Hemisphere is due to a large-scale high surface pressure anomaly poleward of the massif. At a later stage, high pressure and low temperature anomalies develop in the lower troposphere east of the mountain, explaining the signal on $T_{M 2}$ and providing the favorable conditions for the cold surge development.

It is concluded that the EMT is a good measure of the dynamical forcing of the atmospheric flow by the mountains and that the poleward forces exerted by mountains on the atmosphere are substantial drivers of the cold surges, at least in their early stage. Therefore, the EMT time series can be an important diagnostic to assess the representation of mountains in general circulation models.
\end{abstract}

\section{Introduction}

The influence of mountains on meteorology is a problem of longstanding interest. At the synoptic scales, this interest follows the fact that mountains can help the development of cyclones on their lee side or induce cold surges that can travel equatorward along the eastern mountain flanks. The problem of lee cyclogenesis was studied extensively in the 1980s and 1990s. It has been documented in case studies (e.g., Buzzi and Tibaldi 1978; Clark 1990) and numerical studies (Egger 1988) and partly explained by theoretical models (Pierrehumbert 1985; Smith 1984, 1986; Speranza et al. 1985). The cold surges are a growing topic of interest because they are an

Corresponding author address: François Lott, Laboratoire de Météorologie Dynamique, Ecole Normale Supérieure, 24, rue Lhomond, 75231 Paris CEDEX 05, France.

E-mail: flott@lmd.ens.fr important source of atmospheric variability in winter along the eastern flanks of the major mountain ranges (Hsu and Wallace 1985). They are also relevant for the global climate because they connect the meteorology of the midlatitudes to that in the tropics (Garreaud 2001; Chen et al. 2004). As an illustration of this, the East Asian cold surges interact with the winter monsoon over eastern Asia, the South China Sea, the Maritime Continent, and even the Bay of Bengal (Chang et al. 1979; Chang and Lau 1980; Slingo 1998; Tangang et al. 2008; Mailler and Lott 2009).

In mountain meteorology, it is quite common to measure the dynamical influence of mountains on the atmosphere by horizontal forces (e.g., Davies and Phillips 1985; Bessemoulin et al. 1993). In this approach, there is a distinction between the drag forces that are opposed to the low-level winds and the lift forces that are perpendicular to them. At the mesoscale, where the mountain flow dynamics is controlled by gravity waves and includes 


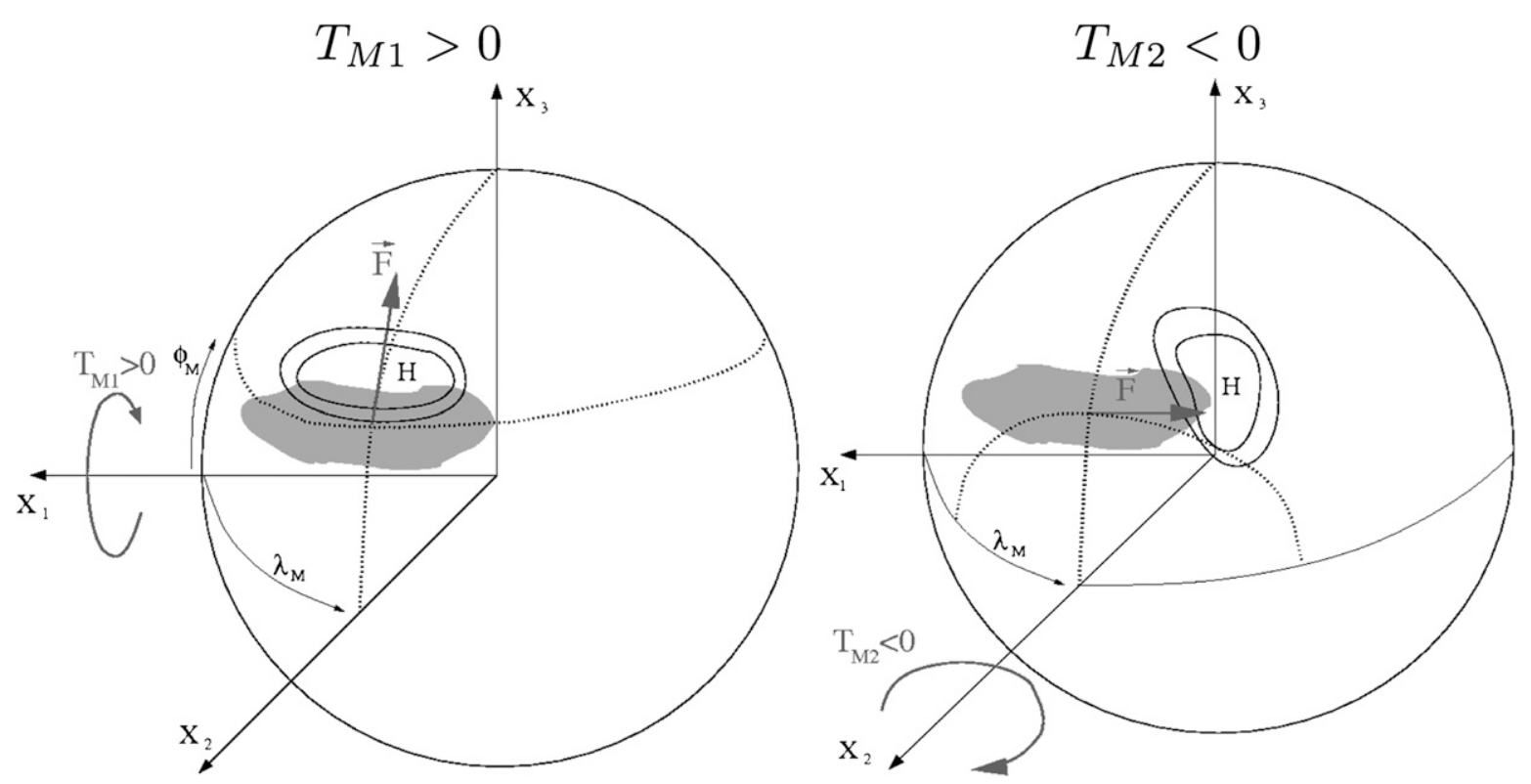

FIG. 1. Schematic pictures of midlatitude and subtropical anomalies in surface pressure yielding to anomalous equatorial torques. This schematic figure is for the Himalayas, and the surface pressure anomalies are representative of two successive stages in the life cycle of an East Asian cold surge. The vector $\mathbf{F}$ is a representation of the dominant horizontal force exerted by the mountain on the atmosphere.

low-level flow blocking, the drag force is very important, whereas at the synoptic and planetary scales the lift force plays a key role and causes vortex compression over mountains (Smith 1979). By triggering baroclinic wave development and forcing planetary-scale waves, these lift forces have an impact on the large-scale atmospheric flow and their proper representation in GCMs is an important issue (Lott 1999).

If we adopt a planetary-scale approach, which is mandatory for large-scale mountains, the atmospheric angular momentum (AAM) budget (Feldstein 2006) provides a more satisfactory formalism to analyze these forces, with the mountain forces translating into torques along the three planetary axes. For example, Mailler and Lott (2009) have shown that before convective events associated with the East Asian winter monsoon, there are strong signals on the equatorial mountain torque (EMT) components $T_{M 1}$ and $T_{M 2}$ due to the Tibetan Plateau (TP). In agreement with other authors (Egger et al. 2007; Egger and Hoinka 2008), they also show that the positive torques along the Greenwich axis are due to a positive surface pressure anomaly to the north of the TP, while the negative torques along the $90^{\circ} \mathrm{E}$ axis are due to a positive pressure anomaly along its eastern slopes (see Fig. 1, where it is also illustrated how a mountain force $\mathbf{F}$ translates into torques along the equatorial axes).

In the past, the analysis of mountain torques was mainly focused on the changes induced in the atmospheric angular momentum and essentially to interpret the changes in the earth orientation parameters (e.g., Rosen and Salstein
1983). In this context, the axial mountain torque $T_{M 3}$ has been analyzed by many authors, including Iskenderian and Salstein (1998), who related the variations of $T_{M 3}$ to the midlatitude dynamics at synoptic scales, and Weickmann and Sardeshmukh (1994), who related its variations to the tropical dynamics at intraseasonal time scales. The two studies cited above are representative of the fact that many authors focused on $T_{M 3}$, whereas $T_{M 1}$ and $T_{M 2}$ have received less attention. Quite recently, however, Feldstein (2006) has analyzed their relation with changes in the equatorial components of the atmospheric angular momentum, and Egger and Hoinka (2008) have described the regional circulation patterns associated with the equatorial torques produced by the TP.

Beyond understanding the axial AAM budget, the axial mountain torque has also been used to measure the dynamical influence of the mountains on the weather and on the climate. It is in this context that Lott et al. (2004) found that $T_{M 3}$ produces changes in the Arctic Oscillation at periodicities below 30 days. Their results, based on diagnostics from the National Centers for Environmental Prediction (NCEP)-National Center for Atmospheric Research (NCAR) reanalysis, have been confirmed using a GCM (Lott et al. 2005) and explained by a simple comprehensive model (Lott and d'Andrea 2005).

Following these lines of work, the purpose of this paper is to show that the temporal evolution of the two components of the EMT is related to the dynamical forcing of the cold surges by the major midlatitude mountain ranges. Emphasis will be given to the TP and 
TABLE 1. Domains over which the integrations in (1a) and (1b) are evaluated to measure the individual contributions of each mountain massif to the global torque, and geographical coordinates of the center of mass for each mountain range. Note that the domain sizes here largely contain the massifs considered.

\begin{tabular}{llll}
\hline \hline \multicolumn{1}{c}{ Massif } & $\begin{array}{c}\text { Longitude } \\
\text { range } \\
{\left[\lambda_{X 1} ; \lambda_{X 2}\right]}\end{array}$ & $\begin{array}{c}\text { Latitude } \\
\text { range } \\
{\left[\phi_{X 1} ; \phi_{X 2}\right]}\end{array}$ & $\begin{array}{c}\text { Center of } \\
\text { mass }\left(\lambda_{X}, \phi_{X}\right)\end{array}$ \\
\hline Andes & {$\left[90^{\circ}-60^{\circ} \mathrm{W}\right]$} & {$\left[60^{\circ} \mathrm{S}-15^{\circ} \mathrm{N}\right]$} & $\left(16.7^{\circ} \mathrm{S}, 70.4^{\circ} \mathrm{W}\right)$ \\
Antarctica & {$\left[180^{\circ} \mathrm{W}-180^{\circ} \mathrm{E}\right]$} & {$\left[90^{\circ}-60^{\circ} \mathrm{S}\right]$} & $\left(83.1^{\circ} \mathrm{S}, 79.7^{\circ} \mathrm{E}\right)$ \\
Greenland & {$\left[70^{\circ}-10^{\circ} \mathrm{W}\right]$} & {$\left[55^{\circ}-85^{\circ} \mathrm{N}\right]$} & $\left(72.0^{\circ} \mathrm{N}, 43.6^{\circ} \mathrm{W}\right)$ \\
Tibetan Plateau & {$\left[60^{\circ}-120^{\circ} \mathrm{E}\right]$} & {$\left[15^{\circ}-60^{\circ} \mathrm{N}\right]$} & $\left(37.8^{\circ} \mathrm{N}, 91.5^{\circ} \mathrm{E}\right)$ \\
Rockies & {$\left[170^{\circ}-90^{\circ} \mathrm{W}\right]$} & {$\left[15^{\circ}-80^{\circ} \mathrm{N}\right]$} & $\left(44.9^{\circ} \mathrm{N}, 111.3^{\circ} \mathrm{W}\right)$ \\
\hline
\end{tabular}

the East Asian cold surges, but the case of the Rockies and the Andes will also be discussed. To establish the link between the EMT and the cold surges, we will use two pieces of independent evidence. The first is based on a statistical analysis of the NCEP reanalysis data for which the two components of the EMT are evaluated globally and for each major mountain range separately. The temporal evolution of the surface patterns of pressure and temperature associated with the two EMT components are then analyzed and compared to those occurring during cold surges. The second is based on an analytical model that gives a comprehensive explanation for the relationship between the EMT components and the cold surges. This model is purely dynamical and only retains two essential features of the cold surge dynamics: the cold surges are related to low-level cold advection from the midlatitudes to the tropics, and they are preceded by high pressure anomalies poleward of the mountain massif. Because of its simplicity, this model is only used to show that mountain forcings, yielding to EMTs with amplitudes comparable with those observed, are largely sufficient to trigger the initial phase of cold surges.

The plan of the paper is as follows. Section 2 presents the statistical analysis. From the NCEP-NCAR reanalysis, we evaluate the two components of the EMT globally and for each major mountain range. For the Rockies, the Andes, and the TP we then perform a composite analysis
TABLE 2. Standard deviation $\left\langle\widetilde{T}_{X 1}^{2}+\widetilde{T}_{X 2}^{2}\right\rangle^{1 / 2}$ for the global EMT and for the regional contributions of each of the major mountain ranges. Units are Hadleys.

\begin{tabular}{lccc}
\hline \multicolumn{1}{c}{ Massif } & All-year & Winter (DJF) & Summer (JJA) \\
\hline Global & 63.6 & 60.3 & 65.2 \\
Antarctica & 50.2 & 36.5 & 58.1 \\
Tibetan Plateau & 21.8 & 26.8 & 14.9 \\
Greenland & 16.8 & 21.1 & 11.2 \\
Rockies & 15.4 & 19.1 & 10.3 \\
Andes & 6.0 & 7.6 & 4.3 \\
\hline
\end{tabular}

of the surface fields keyed to the EMT. Section 3 presents the theoretical model and our interpretation for the relation between the mountain forcing and the EMTs. Section 4 uses the model results to interpret the observational results of section 2 . Section 5 summarizes and discusses the significance of our results for (i) the cold surge preconditioning, (ii) the equatorial atmospheric angular momentum budget, and (iii) the representation of mountains in GCMs.

\section{Statistical analysis}

Our data are taken from the NCEP-NCAR reanalysis (Kalnay et al. 1996) products for the 1979-2007 period. Specifically, we use the surface pressure $P_{S}$, the 0.995 sigma level temperature $T_{50 \mathrm{~m}}$, and the surface elevation $h$. We will also use the tridimensional fields of zonal wind $u$ and temperature $T$. To focus on the subseasonal variability, we will often remove the annual cycle by subtracting the daily climatology obtained by averaging over the 29 years of our dataset. When used, those subseasonal data will be identified by a tilde symbol; for instance, the subseasonal surface pressure will be written $\widetilde{P}_{s}$.

\section{a. Spectral analysis of the equatorial mountain torques}

The two components of the global subseasonal EMT acting on the atmosphere are computed following Feldstein (2006):

$$
\begin{aligned}
& \widetilde{T}_{M 1}(t)=-a^{2} \iint_{\phi, \lambda} h(\lambda, \phi)\left(-\sin \lambda \cos \phi \frac{\partial \widetilde{P}_{s}}{\partial \phi}+\cos \lambda \sin \phi \frac{\partial \widetilde{P}_{s}}{\partial \lambda}\right) d \phi d \lambda, \\
& \widetilde{T}_{M 2}(t)=-a^{2} \iint_{\phi, \lambda} h(\lambda, \phi)\left(\cos \lambda \cos \phi \frac{\partial \widetilde{P}_{s}}{\partial \phi}+\sin \lambda \sin \phi \frac{\partial \widetilde{P}_{s}}{\partial \lambda}\right) d \phi d \lambda,
\end{aligned}
$$

where $a, \phi$, and $\lambda$ are the earth's radius, latitude and longitude, respectively. In (1), $\widetilde{T}_{M 1}$ is the component of the EMT along the equatorial axis, which is at $0^{\circ}$ longitude (the Greenwich axis), and $\widetilde{T}_{M 2}$ is the component 
Cross-Spectrum
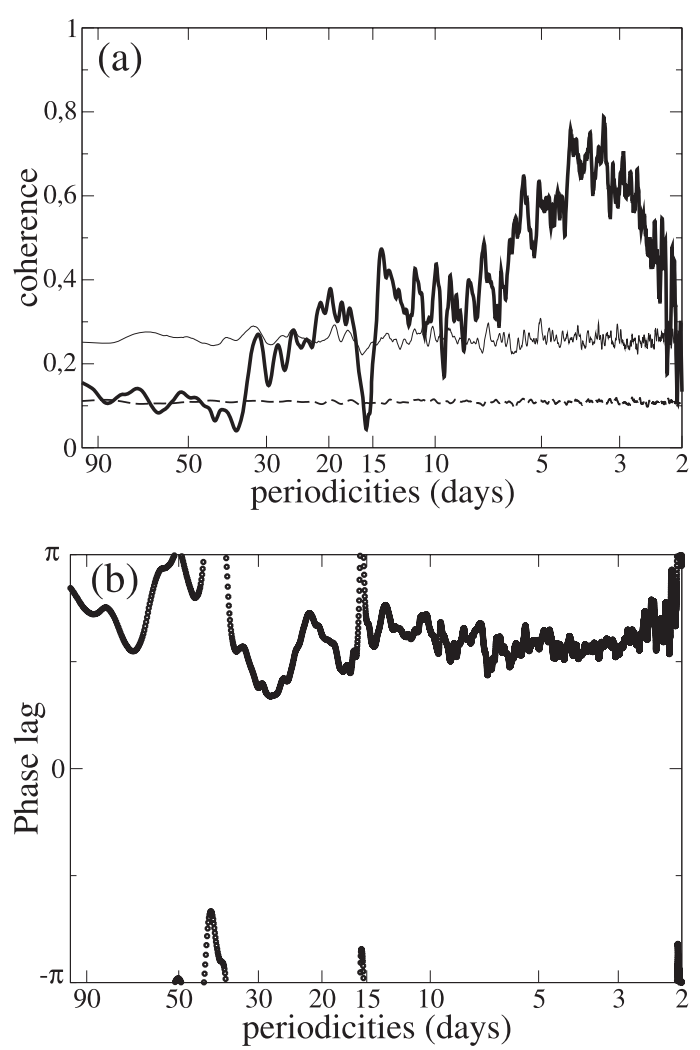

Spectra
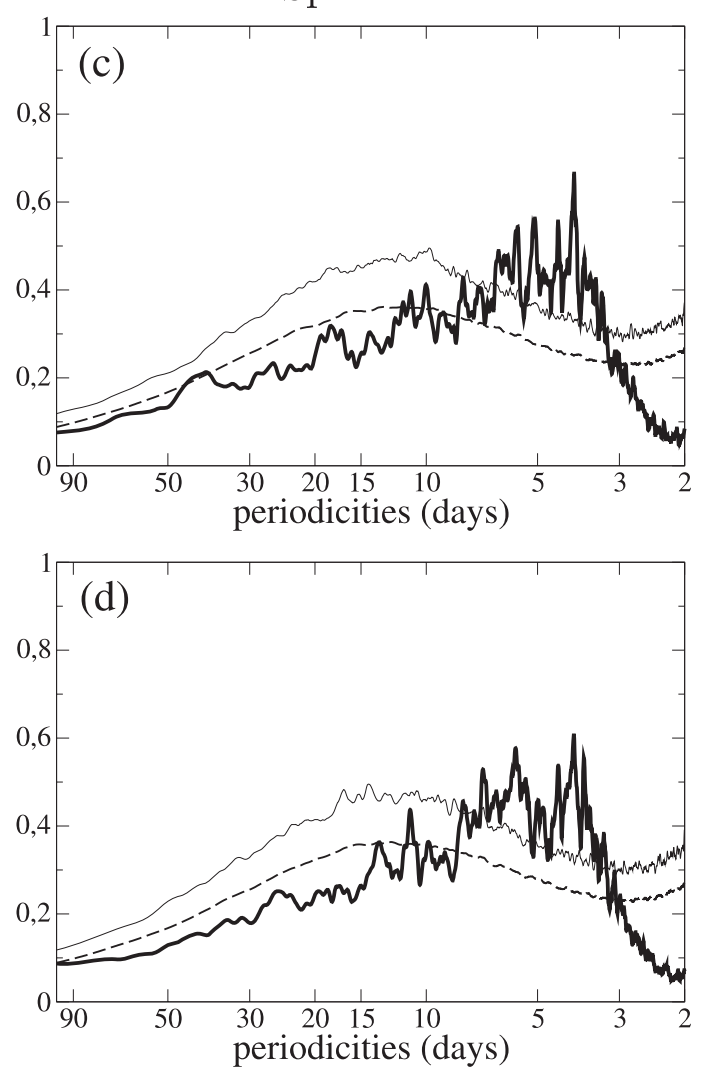

FIG. 2. Spectral analysis of $\widetilde{T}_{M 1}$ and $\widetilde{T}_{M 2}$ : (a) coherency between $\widetilde{T}_{M 1}$ and $\widetilde{T}_{M 2}$, (b) phase difference between $\widetilde{T}_{M 1}$ and $\widetilde{T}_{M 2}$, (c) spectrum of $\widetilde{T}_{M 1}$, and (d) spectrum of $\widetilde{T}_{M 2}$. The spectra and the cross-spectrum are deduced from the two periodograms and the cross periodogram of the series, each of them being smoothed by an 80 -point $10 \%$ cosine window. In the frequency domain this yields a resolution of $8 \times 10^{-2}$ day $^{-1}$. The mean level (gray solid) and the $99 \%$ significance level (gray dashed) are evaluated by a Monte Carlo procedure, which uses an ensemble of 500 pairs of red noise series whose variances and lag-1 autocorrelations correspond to those of $\widetilde{T}_{M 1}$ and $\widetilde{T}_{M 2}$.

along the equatorial axis at $90^{\circ} \mathrm{E}$. Following Egger and Hoinka (2000), we will express all torques in Hadleys (Ha) with $1 \mathrm{Ha} \equiv 10^{18} \mathrm{~kg} \mathrm{~m}^{2} \mathrm{~s}^{-2}$.

The individual contributions of the major mountain ranges (here the TP, the Rockies, the Andes, Antarctica, and Greenland) to the EMT can be computed by restricting the integrations in (1) to sectors including the considered mountain range, which are given in Table 1. Nevertheless, to compare the dynamics associated with the EMT produced by these mountains, the fact that they are located at different places has to be taken into account. For instance, that a northward force applied to the atmosphere around the central location of the TP will mainly result in a positive $\widetilde{T}_{M 1}$ (and a small $\widetilde{T}_{M 2}$ ) is due to the fact that the TP is centered around the longitude $90^{\circ} \mathrm{E}$ (Table 1). In the following we will note this longitude $\lambda_{\mathrm{TP}}$ and also note $\lambda_{X}$ and $\phi_{X}$, the longitude and the latitude of the center of mass of the mountain massif $X$ (with $X=$ TP, R, Ad, At, and G for the TP, Rockies, Andes,
Antarctica, and Greenland, respectively). More precisely, they are the longitude and latitude of the vector

$$
\mathbf{r}_{X}=\frac{\int_{\lambda_{1 X}}^{\lambda_{2 X}} \int_{\phi_{1 X}}^{\phi_{2 X}} h(\lambda, \phi) \mathbf{r}(\lambda, \phi) \cos \phi d \phi d \lambda}{\int_{\lambda_{1 X}}^{\lambda_{2 X}} \int_{\phi_{1 X}}^{\phi_{2 X}} h(\lambda, \phi) \cos \phi d \phi d \lambda},
$$

where $\mathbf{r}(\lambda, \phi)=a(\cos \lambda \cos \phi, \sin \lambda \cos \phi$, $\sin \phi)$, and $\lambda_{1 X}$, $\lambda_{2 X}, \phi_{1 X}$, and $\phi_{2 X}$ are the limits of a region that largely contains the mountain massif considered. These limits as well as $\lambda_{X}$. and the $\phi_{X}$. are given in Table 1 .

To make the results for different mountains comparable, the local equatorial torques for a mountain range $X$ will be computed along equatorial axes rotated by $\lambda_{X}-\pi / 2$, which means that the second equatorial axis is now at the longitude $\lambda_{X}$ of the mountain considered. As said before, this rotation is not needed for the TP and is not adapted for Antarctica, which covers all longitudes. 


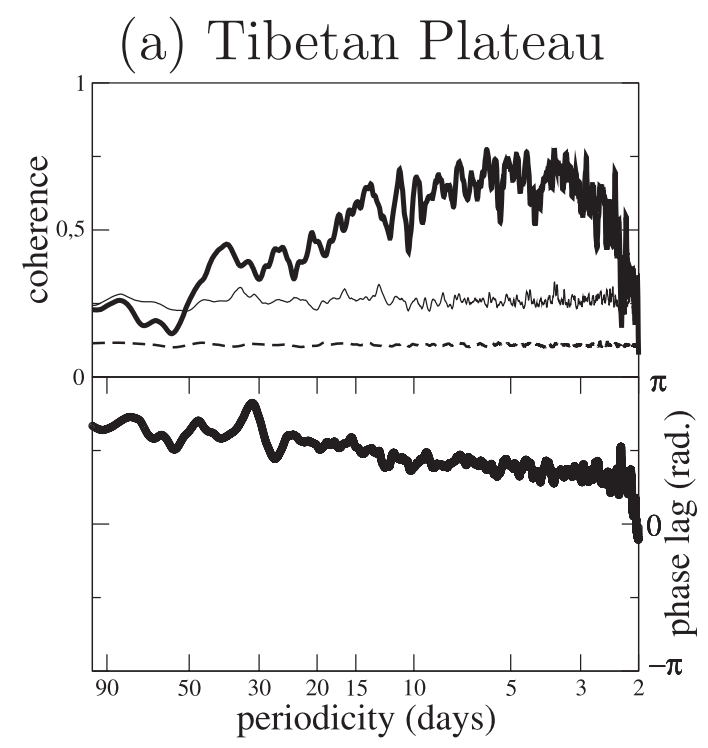

(c) Andes

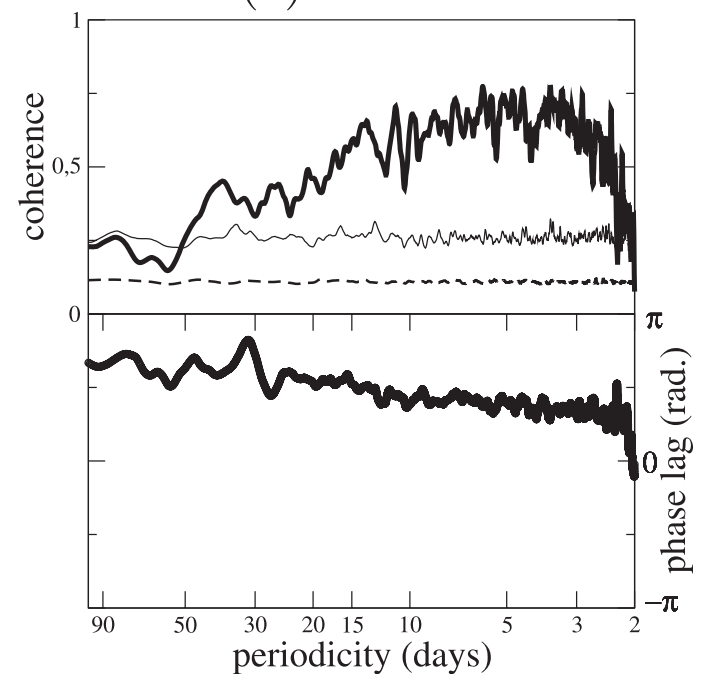

(b) Rockies

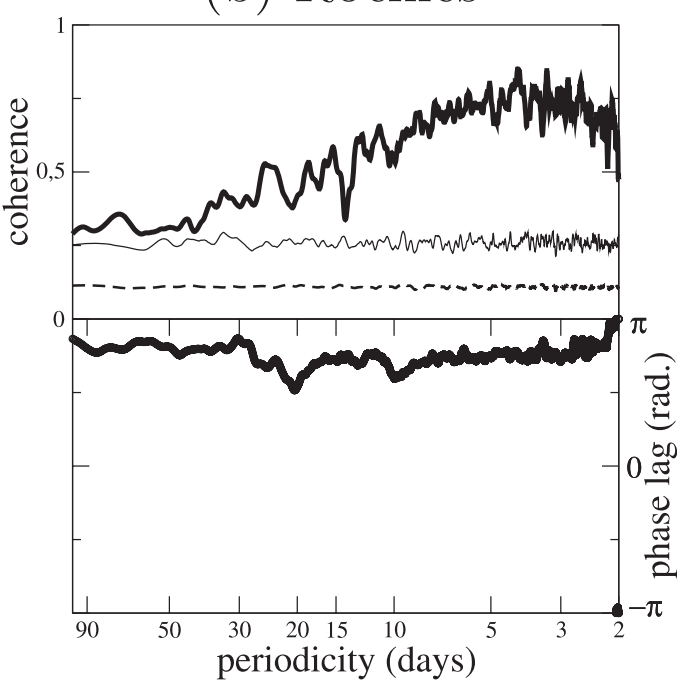

(d) Antarctica

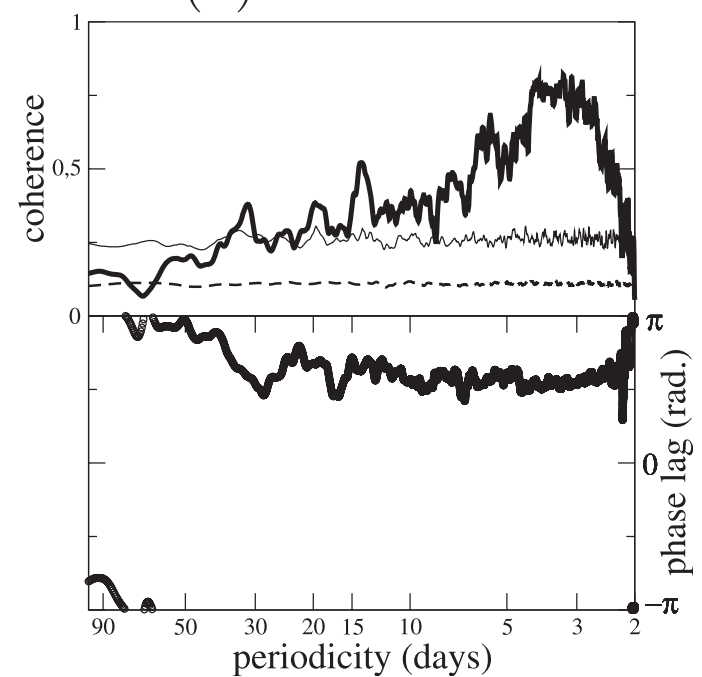

FIG. 3. Coherence and phase relationship between (a) $\widetilde{T}_{\mathrm{TP} 1}$ and $\widetilde{T}_{\mathrm{TP} 2}$ (b) $\widetilde{T}_{\mathrm{R} 1}$ and $\widetilde{T}_{\mathrm{R} 2}$ (c) $\widetilde{T}_{\mathrm{Ad} 1}$ and $\widetilde{T}_{\mathrm{Ad} 2}$ and (d) $\widetilde{T}_{\mathrm{At} 1}$ and $\widetilde{T}_{\mathrm{At} 2}$. Conventions and method are as in Fig. 2 .

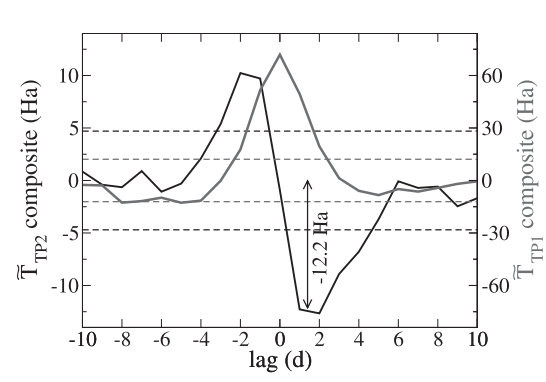

(a)

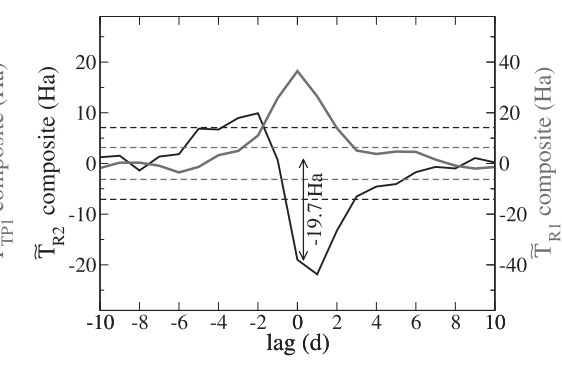

(b)

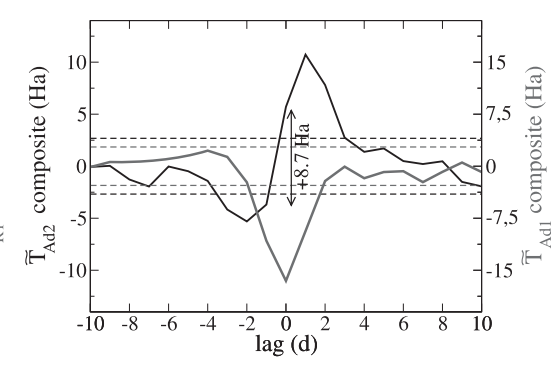

(c)

FIG. 4. (a) Composite time series of $\widetilde{T}_{\mathrm{TP} 1}$ (gray, solid) and $\widetilde{T}_{\mathrm{TP} 2}$ (black, solid) keyed on the 20 strongest positive peaks of $\widetilde{T}_{\mathrm{TP} 1}$ and the corresponding $99 \%$ significance levels. (b) As in (a) but for $\widetilde{T}_{\mathrm{R} 1}$ and $\widetilde{T}_{\mathrm{R} 2}$ keyed on $\widetilde{T}_{\mathrm{R} 1}$. (c) Composite time series of $\widetilde{T}_{\mathrm{Ad} 1}$ and $\widetilde{T}_{\mathrm{Ad} 2}$ keyed on the 20 strongest negative peaks of $\widetilde{T}_{\text {Ad1 }}$. 
In the following, the subseasonal regional contributions to the EMTs expressed in these rotated axes will be denoted $\left(\widetilde{T}_{X 1} ; \widetilde{T}_{X 2}\right)$, where $X$ is the name of the corresponding mountain massif. As an illustration, $\widetilde{T}_{X 1}=0$ and $\widetilde{T}_{X 2}>0$ means that the contribution of the massif $X$ to the EMT vector is oriented along the longitude $\lambda_{X}$. The variance of each of the contributions is given in Table 2, indicating that, while Antarctica is the strongest single contributor, the midlatitude massifs can have a significant impact, at least during the Northern Hemisphere winter.

To characterize the coherence and phase relationship between the two components of the global EMT, we next perform a conventional cross-spectral analysis between the corresponding series (Fig. 2, see caption for details on the method). The cospectrum between $\widetilde{T}_{M 1}$ and $\widetilde{T}_{M 2}$ in Fig. 2 a shows that the two torques are significantly related with each other for periodicities between 2 and 20 days, a spectral domain that contains most of the variance of $\widetilde{T}_{M 1}$ and $\widetilde{T}_{M 2}$ (see Figs. 2c,d). The phase in Fig. $2 \mathrm{~b}$ of nearly $\pi / 2$ shows that $\widetilde{T}_{M 1}$ and $\widetilde{T}_{M 2}$ are close to being in quadrature, with the EMT vector rotating westward.

The same analysis applied to the rotated EMTs associated with the individual mountains in Fig. 3 shows that for the TP, the Rockies, the Andes, and Antarctica, $\widetilde{T}_{X 1}$ and $\widetilde{T}_{X 2}$ are close to being in quadrature as well (Fig. 3), which means that the regional EMT vectors also rotate westward. These results are consistent with those in Egger and Hoinka (2008), who considered the TP only and used lagged correlations rather than a spectral analysis.

The fact that all the regional EMT vectors (except Greenland, not shown) rotate westward like the global EMT indicates that the global behavior of the EMT is, in part, the result of regional circulations, the global EMT vector being the sum of all the regional contributions.

\section{b. Regional circulation patterns}

One of the central points we wish to make is that, when a high pressure anomaly is located poleward of a given mountain massif $X$ in the northern (southern) midlatitudes (i.e., $X=\mathrm{TP}, \mathrm{R}$, or $\mathrm{Ad}$ ), it gives rise to a positive (negative) mountain torque $\widetilde{T}_{X 1}$, and this mountain torque in part controls the future evolution of the flow, triggering a cold surge and a negative (positive) $\widetilde{T}_{X 2}$. To support this picture observationally, composites will be built for the surface fields keyed to the positive peaks of $\widetilde{T}_{\mathrm{TP} 1}$ and $\widetilde{T}_{\mathrm{R} 1}$ and to the negative peaks of $\widetilde{T}_{\mathrm{Ad} 1}$.

In the following, the time lags are expressed in days relative to the peaks in $\widetilde{T}_{X 1}: D 0$ is the day when $\widetilde{T}_{X 1}$ peaks, $D-2$ is two days before, and $D+2$ is two days after. For instance, in the case of the TP at $D 0$, the composite is the average of the values found for the days when $\widetilde{T}_{\mathrm{TP} 1}$ exceeds a given positive threshold. The threshold is chosen so that 20 positive peaks in $\widetilde{T}_{\mathrm{TP} 1}$ are selected, and we impose a 20-day gap between the dates selected. This last restriction, which ensures a statistical independence between the dates selected, allows one to use a Student's $t$ test to evaluate the confidence levels. At $D+l(D-l)$, the composite is built with the values corresponding to the dates situated at the lag $l$ days after (before) the 20 positive peaks identified above.

Figure 4 shows the composites of $\widetilde{T}_{X 2}$ keyed to $\widetilde{T}_{X 1}$ for the TP, the Rockies, and the Andes. In it, we see that for these three massifs, the peaks in $\widetilde{T}_{X 1}$ are followed by peaks of the opposite sign in $\widetilde{T}_{X 2}$. Note that a less significant signal in $\widetilde{T}_{X 2}$ of the same sign as $\widetilde{T}_{X 1}$ tends to precede. This result is consistent with the cross-spectral analysis in Figs. $3 \mathrm{a}-\mathrm{c}$ with $\widetilde{T}_{X 1}$ and $\widetilde{T}_{X 2}$ in quadrature, but provides the additional information that the signal in $\widetilde{T}_{X 2}$ is larger after than before the peaks in $\widetilde{T}_{X 1}$. This is a first indicator that $\widetilde{T}_{X 1}$ contributes to the establishment of $\widetilde{T}_{X 2}$ at a later stage. From a more global viewpoint, we have also analyzed the composites of the global EMT keyed to the regional ones (not shown). In agreement with the results in Table 2, we found that the peaks in the EMTs due to the Rockies and the TP are related to significant signals on both components of the global EMT.

\section{1) Tibetan Plateau}

The composites of $\widetilde{P}_{S}$ and $\widetilde{T}_{50 \mathrm{~m}}$ keyed on the maxima of $\widetilde{T}_{\mathrm{TP} 1}$ in Fig. 5 show that the anomalies of $\widetilde{T}_{\mathrm{TP} 1}$ and $\widetilde{T}_{\mathrm{TP} 2}$ are linked to the clockwise movement of cold temperature and high pressure anomalies around the TP, from Siberia to eastern China. This movement begins at $D-2$ (Figs. 5a,b) with the formation of high pressure and low temperature anomalies centered in western Siberia, later strengthening and moving to central Siberia at $D 0$ (Figs. 5c,d). These anomalies are strong $(16 \mathrm{hPa}$ and $10 \mathrm{~K}$ ) and largely significant. The strong anomaly of surface pressure north of the TP at $D 0$ corresponds to the situation presented in Fig. 1a and explains the peak of $\widetilde{T}_{\mathrm{TP} 1}$ at that time (Fig. 4a).

At $D+2$, the surface pressure and surface temperature anomalies have shifted to eastern China (Figs. 5e,f). At this time, the pressure gradient across the TP is mostly in the zonal direction, corresponding to the schematic picture in Fig. 1b, and this induces a negative $\widetilde{T}_{\mathrm{TP} 2}$ (Fig. $4 a)$. The surface pressure and surface temperature patterns at that time (Figs. 5e,f) are strongly reminiscent of East Asian cold surges (see Fig. 7 of Zhang et al. 1997). Finally, at $D+4$, the anomaly in surface pressure weakens and moves toward the South China Sea. The anomaly in surface temperature remains strong $(7 \mathrm{~K}$ in southeastern China) and moves to the tropics (up to $4 \mathrm{~K}$ in the northern part of the South China Sea), as occurs at 


\section{Lag Surface pressure}

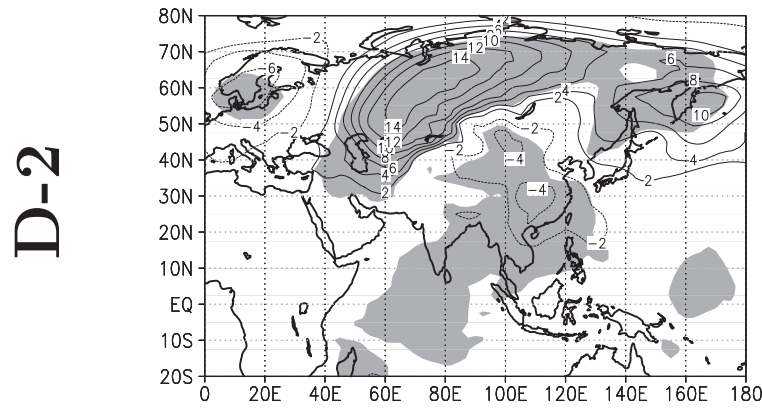

(a)

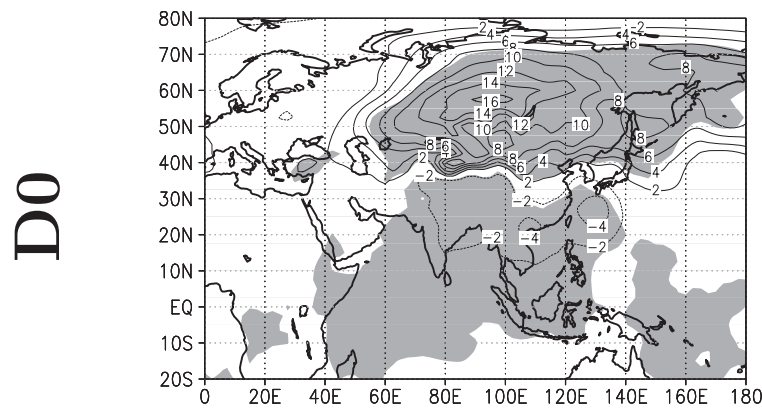

(c)

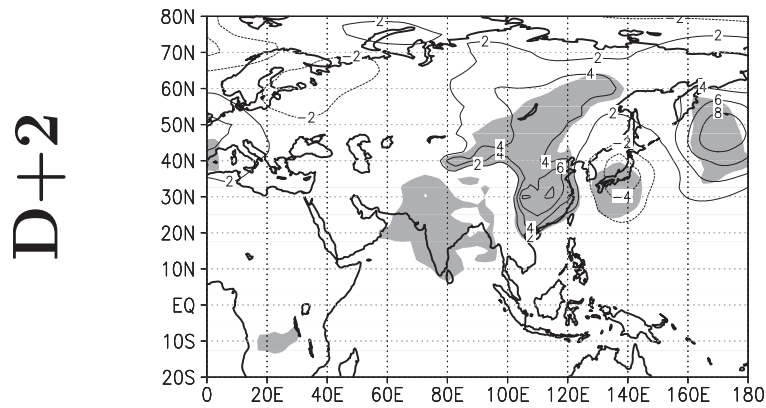

(e)

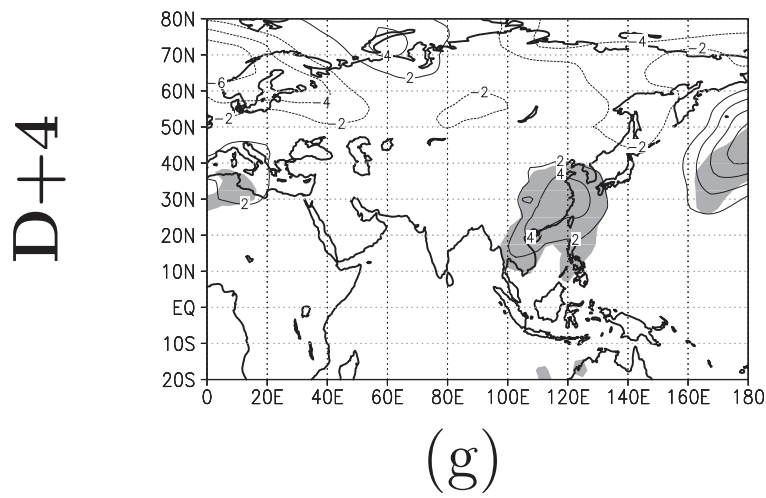

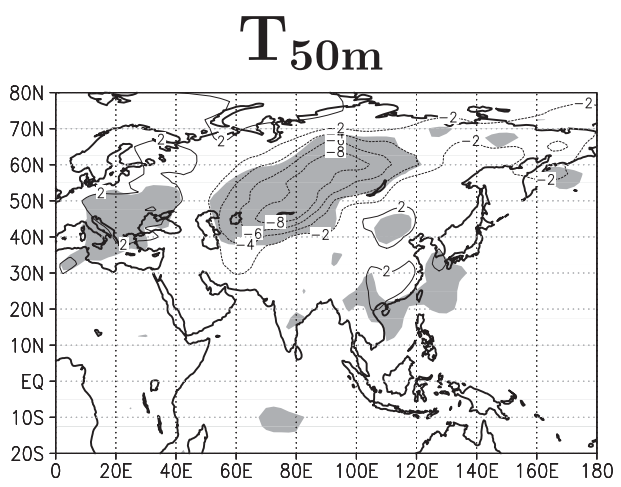

(b)

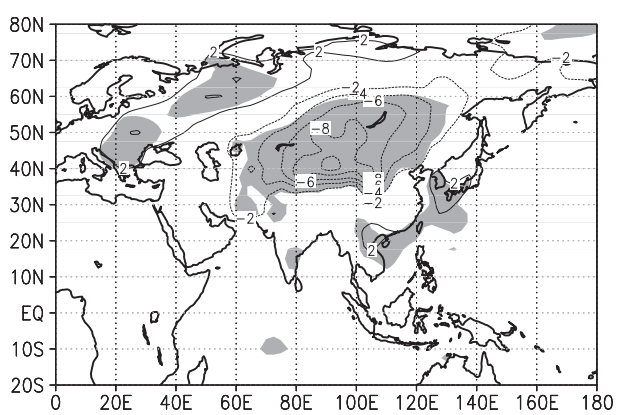

(d)

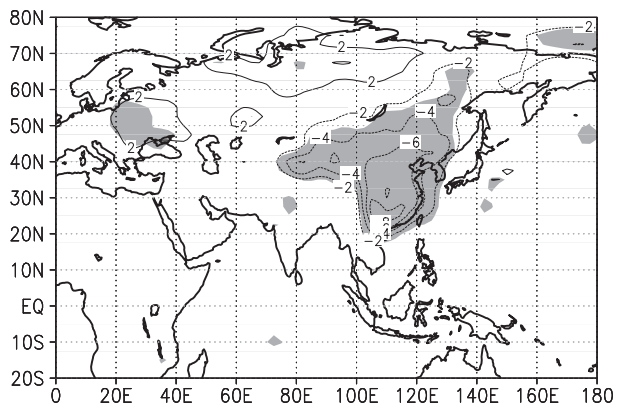

(f)

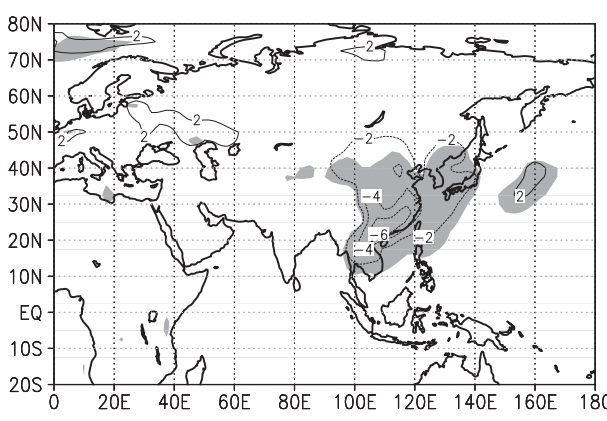

(h)

FIG. 5. Composite of the (left) surface pressure anomalies and (right) surface temperature anomalies for the 20 strongest positive peaks of $\widetilde{T}_{\mathrm{TP} 1}$ at lag (a),(b) $D-2$, (c),(d) $D 0$, (e),(f) $D+2$, and (g),(h) $D+4 ; 99 \%$ confidence level (shaded). Contour interval is $2 \mathrm{hPa}$ for the surface pressures and $2 \mathrm{~K}$ for the surface temperatures: zero contours omitted. 


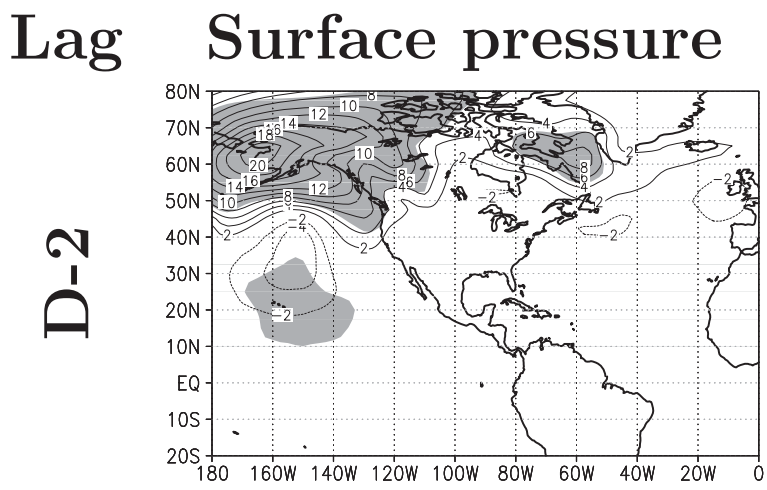

(a)

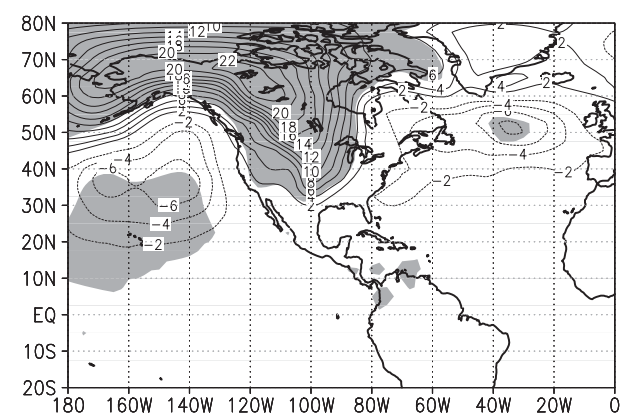

(c)

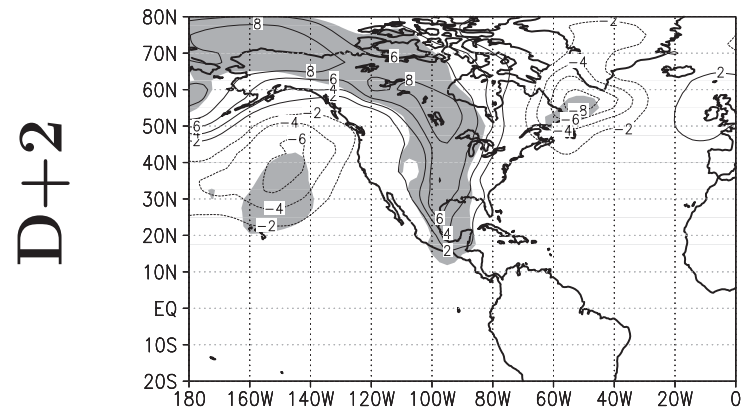

(e)

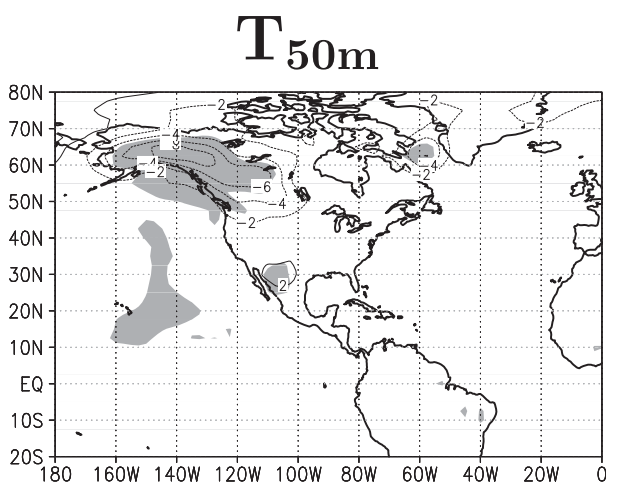

(b)

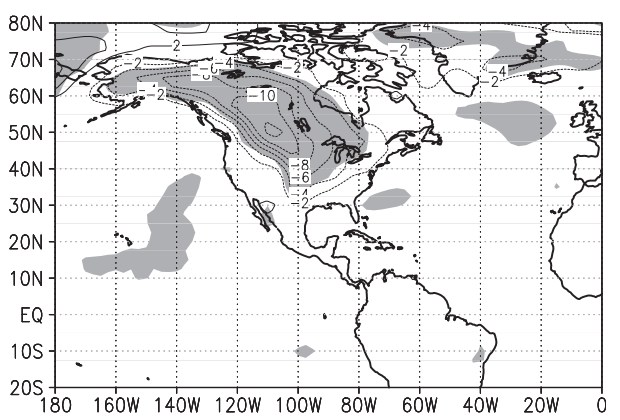

(d)

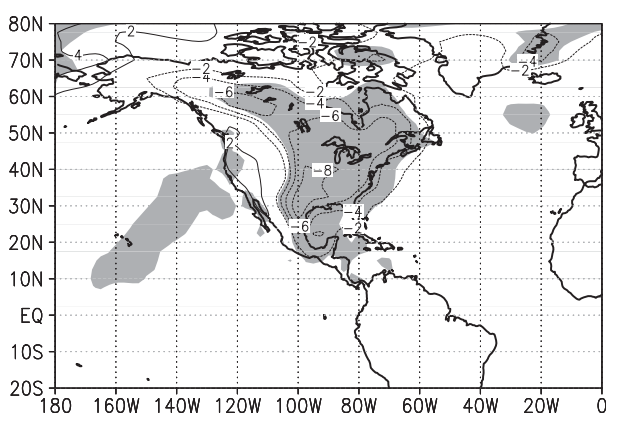

(f)

FIG. 6. As in Fig. 5 but keyed on the positive peaks of $\widetilde{T}_{\mathrm{R} 1}$.

the end of the life cycle of a cold surge (Zhang et al.1997). It is worth noting that the anomalies associated with peaks in $\widetilde{T}_{\mathrm{TP} 1}$ begin their life cycle in the Siberian midlatitudes and finish it 4-6 days later in tropical East Asia.

\section{2) RockIES}

The composites of $\widetilde{P}_{S}$ and $\widetilde{T}_{50 \mathrm{~m}}$ keyed on the maxima of $\widetilde{T}_{\mathrm{R} 1}$ are shown in Fig. 6. These composites are quite similar to those for the TP in Fig. 5: anomalies of high $\widetilde{P}_{S}$ and low $\widetilde{T}_{50 \mathrm{~m}}$ are located over Alaska and the Arctic Ocean at $D-2$ (Figs. 6a,b) and move to the Canadian plains at $D 0$ (Figs. $6 \mathrm{c}, \mathrm{d}$ ), being very strong at this time
(22 $\mathrm{hPa}$ and $12 \mathrm{~K}$ at D0). At $D+2$ (Figs. 6e,f), they stretch southeastward along the eastern flank of the Rockies, covering the Gulf of Mexico and a part of central America. The anomalies displayed at that time are very similar to the structure of the North American cold surges, with cold air masses traveling southward from Canada to the Gulf of Mexico (Colle and Mass 1995) and occasionally reaching the eastern Pacific across Central America (Schultz et al. 1997). At $D+4$ and after, the composites lose significance more rapidly than in the case of the TP (not shown). The shift of the high pressure anomaly from the northwestern slopes 


\section{Lag Surface pressure}

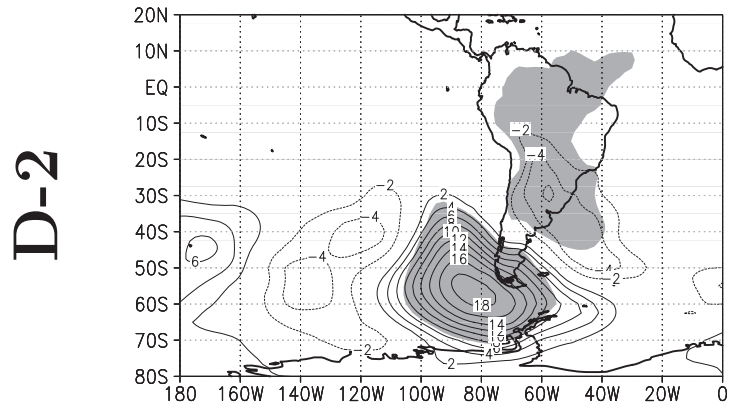

(a)

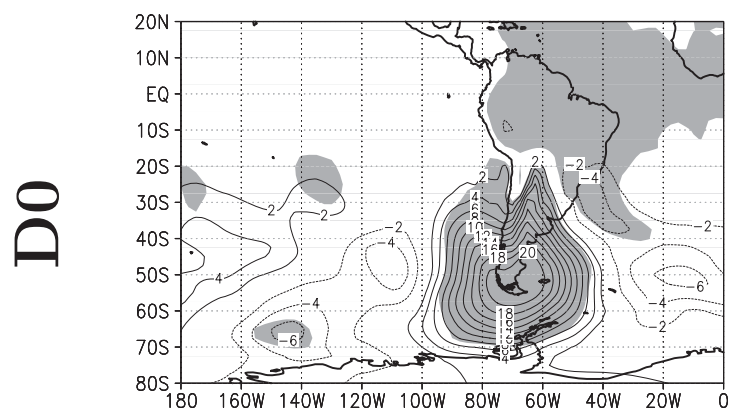

(c)

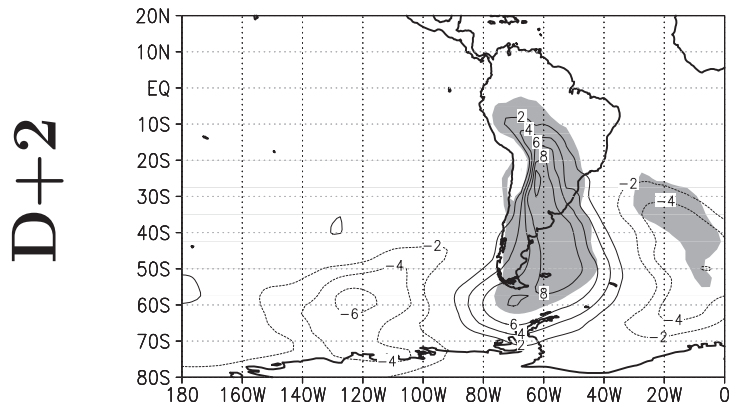

(e)

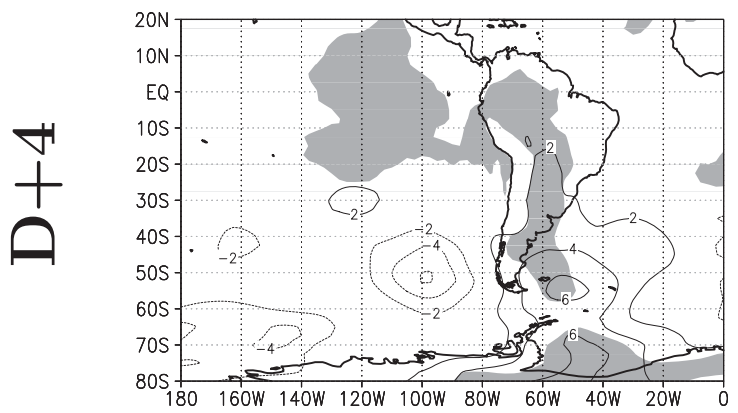

(g)
$\mathrm{T}_{50 \mathrm{~m}}$

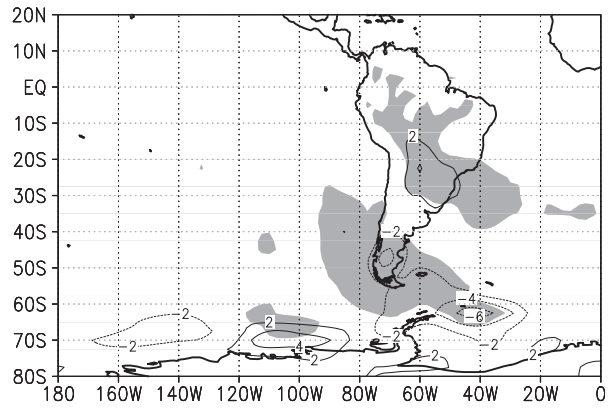

(b)

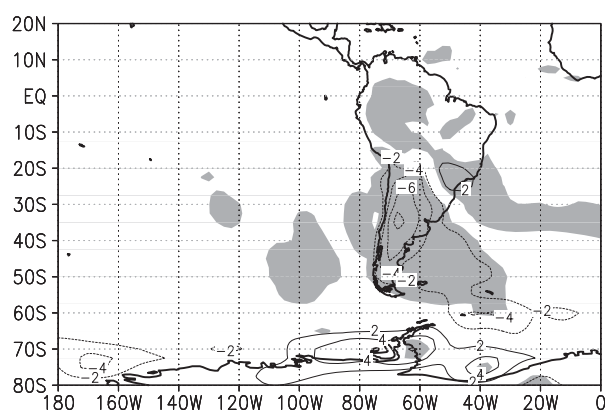

(d)

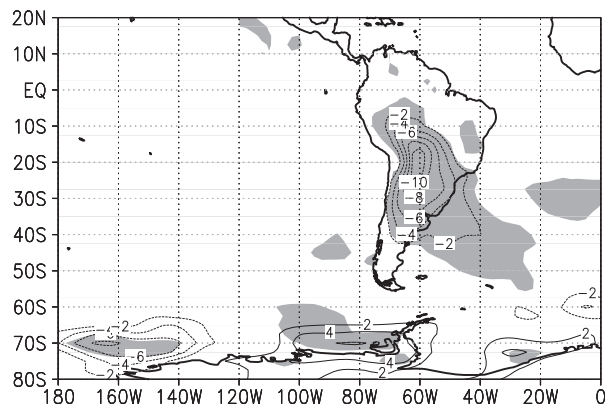

(f)

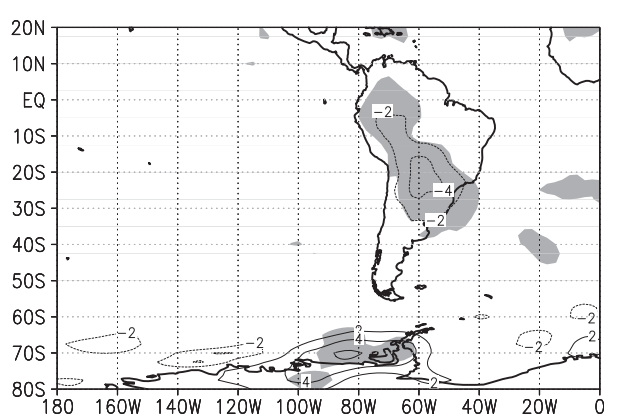

(h)

FIG. 7. As in Fig. 5 but keyed on the negative peaks of $\widetilde{T}_{\text {Ad1 } 1}$. 
of the Rockies to their eastern slopes between $D-2$ and $D+2$ explains that $\widetilde{T}_{\mathrm{R} 2}$ goes from positive to negative values during this period (Fig. $4 \mathrm{~b}$ ).

\section{3) ANDES}

The composites of $\widetilde{P}_{S}$ and $\widetilde{T}_{50 \mathrm{~m}}$ keyed on the minima of $\widetilde{T}_{\text {Ad1 }}$ are in Fig. 7. At $D-2$ (Fig. 7a), a high pressure system is arriving from the Pacific to the southern tip of the Andes. At $D 0$ in Figs. $7 \mathrm{c}$,d, this anticyclone begins to interact substantially with the Andes, with a strong ridge building up along the eastern flank of the mountains. This ridge is associated with a cold anomaly extending meridionally from $50^{\circ}$ to $20^{\circ} \mathrm{S}$ along the eastern flank of the Andes. At $D+2$ the signal on the eastern flank of the Andes becomes even more pronounced (reaching $10 \mathrm{hPa}$ and $-10 \mathrm{~K}$ around $25^{\circ} \mathrm{S}$ ). These strong anomalies at subtropical latitudes are quite remarkable and correspond to the ones generated by the South American cold surges (Seluchi and Nery 1992; Marengo et al. 1997; Garreaud 2000), suggesting that negative events on $\widetilde{T}_{\mathrm{Ad} 1}$ are an important factor in the generation of these events. Similarly to what happens in the case of the TP (Fig. 5), the low temperature and high surface pressure anomaly have moved farther into the tropics at $D+4$ (Fig. $7 \mathrm{~g}$ ), being significant as far north as $5^{\circ} \mathrm{N}$. The evolution of the surface pressure patterns explains the evolution of the composite $\widetilde{T}_{\mathrm{Ad} 2}$ as shown in Fig. 4c: $\widetilde{T}_{\mathrm{Ad} 2}$ has a negative peak at $D-2$ when the high pressure arrives from the Pacific Ocean and reaches the western slopes of the Andes (Fig. 7a), then $\widetilde{T}_{\text {Ad2 }}$ has a positive tendency at D0 owing to the ridge formation along the eastern mountain slopes (Fig. 7c) and reaches strong positive values at $D+1$ and $D+2$ when the ridge further strengthens and moves northward along the mountain (Fig. 7e).

\section{Theoretical model}

\section{a. Basic equations}

To interpret the temporal evolution of the EMT vector and its relation with the surface fields discussed in section 2 , we will next use a linear model based on the quasigeostrophic $(\mathrm{QG}) f$-plane approximation of the anelastic equations on the sphere. In this model, we will impose a background zonal geostrophic wind $\bar{u}_{g}(\phi, z)$ in thermal wind balance with a background potential temperature $\bar{\theta}(\phi, z)$,

$$
f \bar{u}_{g z}=\frac{g}{a \theta_{0}} \bar{\theta}_{\phi}
$$

with the Coriolis parameter $f=2 \Omega \sin \phi_{r}$, where $\phi_{r}$ is a constant reference latitude. Still in (3), $\theta_{0}(z)$ is a background potential temperature corresponding to the atmosphere at rest. In this linear framework, the equations for the disturbance produced by the mountain are

$$
\begin{aligned}
& \left(\frac{\partial}{\partial t}+\frac{\bar{u}_{g}}{a \cos \phi} \frac{\partial}{\partial \lambda}\right) u_{g}^{\prime}+\frac{\left(\bar{u}_{g} \cos \phi\right)_{\phi}}{a \cos \phi} v_{g}^{\prime}-f v^{\prime} \\
& =-\frac{1}{a \cos \phi} \frac{\partial \Phi^{\prime}}{\partial \lambda}, \\
& \left(\frac{\partial}{\partial t}+\frac{\bar{u}_{g}}{a \cos \phi} \frac{\partial}{\partial \lambda}\right) v_{g}^{\prime}+2 \frac{\bar{u}_{g} u_{g}^{\prime}}{a} \tan \phi+f u^{\prime} \\
& =-\frac{1}{a} \frac{\partial \Phi^{\prime}}{\partial \phi}+\frac{F^{\prime}}{\rho_{r}} \delta(z), \\
& \frac{\partial \Phi^{\prime}}{\partial z}-g \frac{\theta^{\prime}}{\theta_{0}}=0, \\
& \frac{\rho_{0}}{a \cos \phi}\left(\frac{\partial u^{\prime}}{\partial \lambda}+\frac{\partial v^{\prime} \cos \phi}{\partial \phi}\right)+\frac{\partial \rho_{0} w^{\prime}}{\partial z}=0, \\
& \left(\frac{\partial}{\partial t}+\frac{\bar{u}_{g}}{a \cos \phi} \frac{\partial}{\partial \lambda}\right) \theta^{\prime}+\frac{\bar{\theta}_{\phi}}{a} v_{g}^{\prime}+\frac{d \theta_{0}}{d z} w^{\prime} \\
& =Q^{\prime}(\lambda, \phi) \frac{\theta_{0 z}}{\rho_{0}},
\end{aligned}
$$

and the linear lower boundary condition is

$$
w^{\prime}(z=0)=\frac{\bar{u}_{g}}{a \cos \phi} \frac{\partial h}{\partial \lambda} .
$$

In (4a-e) and (5), the prime variables are for the disturbance fields produced by the mountain; $\rho_{0}(z)$ is a background density profile; $\rho_{r}=\rho_{0}(z=0) ; u_{g}$ and $v_{g}$ are the two components of the geostrophic wind, where

$$
u_{g}=-\frac{1}{a f} \frac{\partial \Phi}{\partial \phi} ; \quad v_{g}=\frac{1}{a f \cos \phi} \frac{\partial \Phi}{\partial \lambda}
$$

$u, v$, and $w$ are the three components of the wind; and $\theta$ is the potential temperature.

Two unconventional terms are introduced in (4b) and (4e). The first is the lateral force $F^{\prime} \delta(z) / \rho_{r}$ in which $\delta(z)$ is the Dirac distribution. It will only be used in a formal way to clarify the relation between the mountain forces applied to the atmosphere and the more conventional boundary condition in (5). In (4e) the diabatic term $Q^{\prime}(\lambda$, $\phi) \theta_{0 z} / \rho_{0}$ will be used to represent more realistically the interaction between the low-level wind and the mountain (see section 3).

\section{b. Model description}

To analyze the response in our model, we will first follow Bretherton (1966) and assume that (4a)-(4e), 
which are written for $z \geq 0$, are valid for all $z$ once multiplied by the Heaviside function $\mathcal{H}(z)$. Hence, if we derive a potential vorticity (PV) budget from (4a)-(4e), we obtain the PV equation

$$
\begin{aligned}
& {\left[\left(\frac{\partial}{\partial t}+\frac{\bar{u}_{g}}{a \cos \phi} \frac{\partial}{\partial \lambda}\right) q_{g}^{\prime}+\frac{v_{g}^{\prime}}{a} \bar{q}_{g \phi}\right] \mathcal{H}(z)} \\
& \quad+\left[\left(\frac{\partial}{\partial t}+\frac{\bar{u}_{g}}{a \cos \phi} \frac{\partial}{\partial \lambda}\right) f \frac{\Phi_{z}^{\prime}}{N^{2}}-\frac{f^{2} \bar{u}_{g z}}{N^{2}} v_{g}^{\prime}+f w^{\prime}\right. \\
& \left.\quad-\frac{F_{\lambda}^{\prime}}{\rho_{r} a \cos \phi}-\frac{f Q^{\prime}}{2 \theta_{0 z}}\right] \delta(z)=0
\end{aligned}
$$

where $\delta(z)=\mathcal{H}_{z}(z)$. Equation (7) can only be satisfied if the terms within the two pairs of brackets are null separately. In the first bracket of (7) the inflow QG PV is given by

$$
q_{g}=\frac{v_{g \lambda}-\left(u_{g} \cos \phi\right)_{\phi}}{a \cos \phi}+\frac{f}{\rho_{0}}\left(\frac{\rho_{0} \Phi_{z}}{N^{2}}\right)_{z} .
$$

To represent a high surface pressure anomaly poleward of the mountain, we impose a negative background low-level wind $\bar{u}_{g}\left(\phi_{r}, z=0\right)<0$. To represent the subtropic to pole negative temperature gradient, we will consider that the background wind has a positive vertical wind shear characterized by the constant $\Lambda>0$,

$$
\bar{u}_{g}(\phi, z)=\left(u_{r}+\Lambda z\right) \cos \phi
$$

where $u_{r}<0$ is a constant and the $\cos \phi$ dependence is introduced because it simplifies considerably the lower boundary condition given in the second bracket of (7). The zonal wind in (9) has a mean QG PV

$$
\begin{aligned}
\bar{q}_{g} & =-\frac{\left(\bar{u}_{g} \cos \phi\right)_{\phi}}{a \cos \phi}+\frac{f\left(\rho_{0} \bar{\Phi}_{z}\right)_{z}}{N^{2} \rho_{0}} \\
& =\left(2 \frac{u_{r}+\Lambda z}{a}+\frac{a f^{2} \Lambda}{N^{2} H}\right) \sin \phi,
\end{aligned}
$$

which varies in the meridional direction. Nevertheless, its meridional gradient $\bar{q}_{g \phi} / a$ compares in amplitude with the planetary PV gradient. As the planetary PV gradient is not taken into account in the $f$-plane approximation we make, we will consistently neglect the influence of $\bar{q}_{g \phi}$ on the evolution of the disturbances. With this approximation, the disturbance inflow PV $q_{g}^{\prime}$ in the first bracket of (7) stays null if it is null at $t=0$, yielding

$$
\Delta \Phi^{\prime}+\frac{f^{2}}{\rho_{0}}\left(\frac{\rho_{0} \Phi_{z}^{\prime}}{N^{2}}\right)_{z}=0
$$

where

$$
\Delta=\frac{1}{a^{2} \cos \phi} \frac{\partial}{\partial \phi} \cos \phi \frac{\partial}{\partial \phi}+\frac{1}{a^{2} \cos ^{2} \phi} \frac{\partial^{2}}{\partial \lambda^{2}} .
$$

Using the kinematic boundary condition (5), the lower boundary condition in the second bracket of (7) becomes

$$
\left(\partial_{t}+\frac{u_{r}}{a} \partial_{\lambda}\right) \Phi_{z}^{\prime}-\frac{\Lambda}{a} \frac{\partial \Phi^{\prime}}{\partial \lambda}=-\frac{N^{2} u_{r}}{a} \frac{\partial h}{\partial \lambda},
$$

where we have set the unconventional terms $F^{\prime}=Q^{\prime}=0$. The solutions to (11) and (12) can be computed using the spherical harmonic functions $Y_{l}^{m}(\lambda, \phi)$, where $\Delta Y_{l}^{m}=$ $-a^{-2} l(l+1) Y_{l}^{m}$ and $\partial_{\lambda} Y_{l}^{m}=i m Y_{l}^{m}$. In this formalism, we can project $\Phi^{\prime}$ and $h$ on the functions $Y_{l}^{m}$,

$$
\begin{aligned}
\Phi^{\prime}(\lambda, \phi, z, t) & =\sum_{l=1}^{L} \sum_{m=-l}^{+l} \Phi_{l}^{m}(t) e^{-k_{l} z} Y_{l}^{m}(\lambda, \phi), \\
h(\lambda, \phi) & =\sum_{l=1}^{L} \sum_{m=-l}^{+l} h_{l}^{m}(t) Y_{l}^{m}(\lambda, \phi),
\end{aligned}
$$

where $L$ is the truncation and

$$
k_{l}=\left(\frac{1}{4 H^{2}}+\frac{N^{2}}{f^{2}} \frac{l(l+1)}{a^{2}}\right)^{1 / 2}-\frac{1}{2 H}>0 .
$$

The exponential term in (13a) ensures that the disturbance has $0 \mathrm{PV}$ and vanishes at $z=\infty$. If we take as the initial condition that the flow at $t=0$ is undisturbed $\left(\Phi_{l}^{m}=0\right.$ at $\left.t=0\right)$, then a solution that satisfies the linear boundary condition in (12) is

$$
\begin{aligned}
\Phi_{l}^{m}(t)= & \left\{\left[1-\exp \left(-\frac{i m u_{r}}{a k_{l}}\left(k_{l}+\Lambda / u_{r}\right) t\right)\right] /\left(k_{l}+\Lambda / u_{r}\right)\right\} \\
& \times N^{2} h_{l}^{m} .
\end{aligned}
$$

\section{c. Equatorial mountain torques in the model}

We can calculate two different contributions to the equatorial torques from our model. The first is the one associated with the background surface pressure gradient,

$$
f \bar{u}_{g}(0)=-\frac{1}{a} \frac{\partial \bar{\Phi}_{s}}{\partial \phi}=-\frac{1}{\rho_{r}} \frac{1}{a} \frac{\partial \bar{P}_{s}}{\partial \phi},
$$

that is present at the initial time in our model. If we take $\bar{P}_{s}$ for the pressure in the equatorial torques in (1a) and (1b), we obtain at $t=0$

$$
\begin{aligned}
\hat{T}_{X 1} & =-a^{3} f \rho_{r} \iint \sin \lambda \cos \phi \bar{u}_{g}(\phi) h(\lambda, \phi) d \lambda d \phi \\
& \approx-a f \rho_{r} \bar{u}_{g}\left(\phi_{r}\right) V>0(\mathrm{NH}),
\end{aligned}
$$




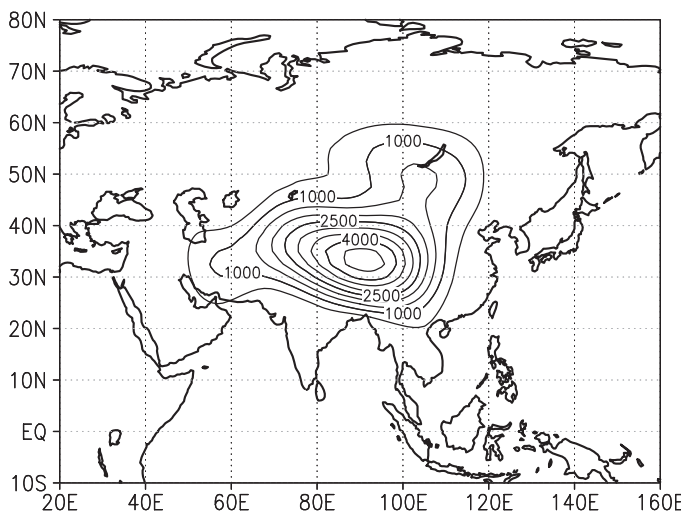

(a)

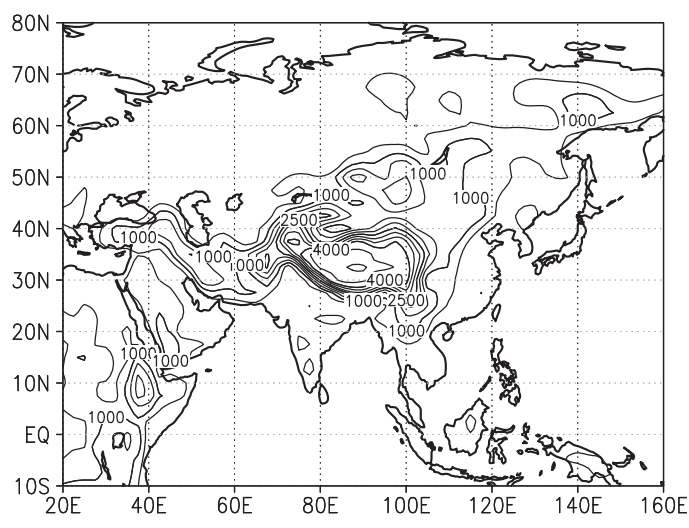

(b)

FIG. 8. (a) Topography retained for the model run and (b) NCEP topography (m MSL). The model topography is obtained by multiplying the T21-filtered NCEP topography by $\alpha(\lambda) \beta(\phi)$, where $\alpha(\lambda)[\beta(\phi)]$ is a function whose value is 1 in the interval $\left(\lambda_{1} ; \lambda_{2}\right)\left[\left(\phi_{1} ; \phi_{2}\right)\right]$ corresponding to the longitude (resp. latitude) range in Table $1 ; 0$ outside $\left(\lambda_{1}-\right.$ $\left.15^{\circ} ; \lambda_{2}+15^{\circ}\right)\left[\left(\phi_{1}-15^{\circ} ; \phi_{2}+15^{\circ}\right)\right]$; and a smooth connection is ensured by the use of an exponential taper $\varphi(t)=$ $\exp \left[t^{2} /\left(t^{2}-1\right)\right]$.

$\hat{T}_{X 2}=a^{3} f \rho_{r} \iint \cos \lambda \cos \phi \bar{u}_{g}(\phi) h(\lambda, \phi) d \lambda d \phi \approx 0$,

where the caret indicates that these torques are issued from the model. For each massif, they are expressed in the rotated axis system used to define the regional torques in section 2. The approximate values to the right of (17a) and (17b), where $V$ is the mountain volume, are given to indicate that at $t=0$ the EMT is essentially along the first rotated equatorial axis, simply because $\sin \lambda \approx 1$ and $\cos \lambda \approx 0$ where the mountain is located and according to the rotated axes. The sign for $\hat{T}_{X 1}$ is related to the fact that $u_{r}<0$ and to the sign of the Coriolis parameter, so it is positive in the Northern Hemisphere [NH in (17a)] and negative in the Southern Hemisphere.

In this paper we argue that those torques measure the dynamical forcing of the mountain on the flow. This assumption is not so obvious at this stage since the evaluation of the torque in (1) is just a diagnostic where a given surface pressure field is placed in given integrals. To illustrate how this torque impacts the future evolution of the flow, it is worth noting that the model equation (7) remains unchanged if we impose $h=0$ in the boundary condition (5) but take the topography into account by the introduction of a surface stress:

$$
w^{\prime}(z=0)=0, \quad F^{\prime}=-\rho_{r} f \bar{u}_{g}(\phi, z=0) h .
$$

Note also that the stress $F^{\prime}$ in (18) corresponds to the lift force associated with vortex compression by mountains in Smith (1979), which was introduced in a GCM by Lott (1999) to reduce its systematic errors.

To translate $F^{\prime}$ into a torque, we form the cross product between the position vector $\mathbf{r}$ and the momentum equations (4a) and (4b) and integrate over all the atmosphere. When doing so, the EMT vector due to the surface stress $F^{\prime}$ is

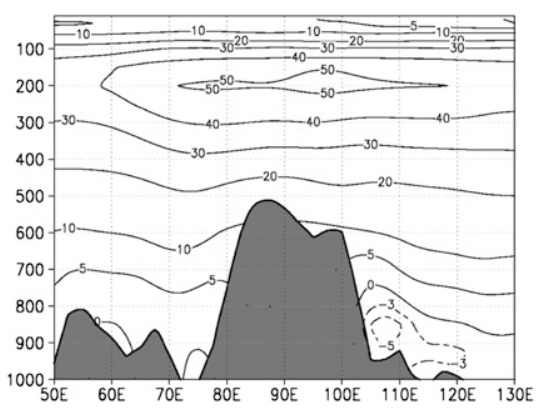

(a)

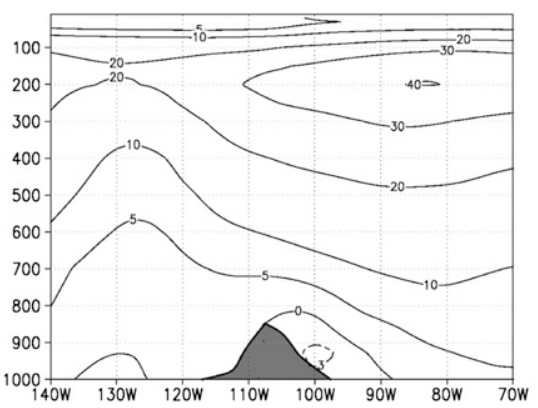

(b)

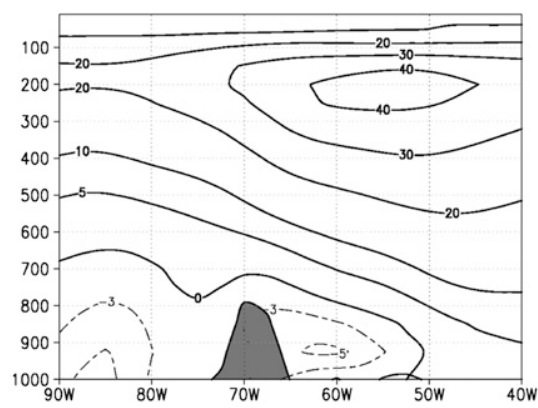

(c)

FIG. 9. (a) Composite of the zonal wind at $30^{\circ} \mathrm{N}$ keyed on the 20 strongest positive peaks of $\widetilde{T}_{\mathrm{TP} 1}$; (b) as in (a) but for the composite keyed on $\widetilde{T}_{\mathrm{R} 1}$; (c) composite of the zonal wind at $30^{\circ} \mathrm{S}$ keyed on the 20 strongest negative peaks of $\widetilde{T}_{\mathrm{Ad} 1}$. The contours are every $10 \mathrm{~m} \mathrm{~s}{ }^{-1}$ for positive (westerly) winds and at -3 and $-5 \mathrm{~m} \mathrm{~s}^{-1}$ for negative (easterly) winds. 
TABLE 3. Percentage of error between the raw mountain torque series and the mountain torque series evaluated after filtering the orography and the surface pressure at different truncations. For all series the annual cycle has been subtracted. For the regional torques the filtered orography is also tapered by the smooth plateau function described in section $4 \mathrm{a}$. For a given mountain $X$, a given equatorial axis $i$, and a given truncation Tnn, the values shown correspond to square of the error: $\left(\epsilon_{X i}^{\mathrm{Tnn}}\right)^{2}=\left\langle\left(\tilde{T}_{X i}-\tilde{T}_{X i}^{\mathrm{Tnn}}\right)^{2}\right\rangle /\left\langle\tilde{T}_{X i}^{2}\right\rangle$.

\begin{tabular}{|c|c|c|c|c|c|c|c|c|c|c|c|c|}
\hline & \multicolumn{2}{|c|}{ Global } & \multicolumn{2}{|c|}{$\mathrm{TP}$} & \multicolumn{2}{|c|}{ Antarctica } & \multicolumn{2}{|c|}{ Rockies } & \multicolumn{2}{|c|}{ Greenland } & \multicolumn{2}{|c|}{ Andes } \\
\hline & $\widetilde{T}_{M 1}$ & $\widetilde{T_{M 2}}$ & $\widetilde{T}_{\mathrm{TP} 1}$ & $\widetilde{T}_{\mathrm{TP} 2}$ & $\widetilde{T}_{\text {At1 }}$ & $\widetilde{T}_{\mathrm{At} 2}$ & $\widetilde{T}_{\mathrm{R} 1}$ & $\widetilde{T}_{\mathrm{R} 2}$ & $\widetilde{T}_{G 1}$ & $\widetilde{T}_{G 2}$ & $\widetilde{T}_{\text {Ad1 }}$ & $\widetilde{T}_{\mathrm{Ad} 2}$ \\
\hline T63 & $<1 \%$ & $<1 \%$ & $<1 \%$ & $<1 \%$ & $<1 \%$ & $<1 \%$ & $<1 \%$ & $<1 \%$ & $<1 \%$ & $<1 \%$ & $<1 \%$ & $<1 \%$ \\
\hline $\mathrm{T} 42$ & $<1 \%$ & $<1 \%$ & $<1 \%$ & $<1 \%$ & $<1 \%$ & $<1 \%$ & $<1 \%$ & $<1 \%$ & $<1 \%$ & $<1 \%$ & $<1 \%$ & $1.9 \%$ \\
\hline $\mathrm{T} 21$ & $3 \%$ & $3.4 \%$ & $5.6 \%$ & $6.1 \%$ & $2.3 \%$ & $3.8 \%$ & $2.1 \%$ & $4.3 \%$ & $19 \%$ & $25 \%$ & $12 \%$ & $23 \%$ \\
\hline $\mathrm{T} 10$ & $41 \%$ & $26 \%$ & $62 \%$ & $32 \%$ & $40 \%$ & $19.6 \%$ & $24 \%$ & $42 \%$ & $92 \%$ & $129 \%$ & $44 \%$ & $124 \%$ \\
\hline
\end{tabular}

$\mathbf{T}_{F^{\prime}}=a^{3} \iint_{\lambda, \phi} F^{\prime}(\cos \phi \sin \lambda,-\cos \phi \cos \lambda) d \phi d \lambda$

If we use $F^{\prime}$ from (18), the torque in (19) is exactly equal to the initial torque in (1), provided that $\partial \bar{P}_{S} / \partial \phi=$ $-a f \rho_{r} \bar{u}_{g}(\phi, z=0)$. As $F^{\prime}$ now (i) is the only forcing in the model, (ii) is purely dynamical, and (iii) builds up a global torque exactly equal to the equatorial mountain torques, it is justified to say that the equatorial mountain torque measures the dynamical forcing of the flow by the mountain.

The mountain torque predicted by the model and using the torque expressions (1a) and (1b) evolves simply because the surface pressure field $\rho_{r} \Phi(z=0)$ is not constant. Nevertheless, the evolution of the torque in this case is purely diagnostic because the disturbance signal does not interact in return with the orography (the model is linear). It means that this model can explain how an initial torque along the first axis $\hat{T}_{X 1}$ produces a torque along the second axis $\hat{T}_{X 2}$ at a later stage, but it cannot tell how this second torque can affect $\hat{T}_{X 1}$ in return. Hence, we will always present $\hat{T}_{X 1}(t=0)$, resulting from the background flow only, and $\hat{T}_{X 2}(t=1 \mathrm{~d})$. Note that $\hat{T}_{X 2}(t=1 \mathrm{~d})$ is essentially due to the disturbance field since the contribution of the background flow to it is small [see (17b)].

\section{Model results and comparison with the composites}

\section{a. Experimental setup}

With the model described above, we analyzed the cases of the TP, the Rockies, and the Andes. In latitude, we will center our model at a latitude $\phi_{r}$ that is in between the midlatitudes and the subtropics, with $\phi_{r}=+30^{\circ} \mathrm{N}$ for the
$\mathrm{TP}$ and the Rockies and $\phi_{r}=-30^{\circ} \mathrm{S}$ for the Andes. We will also assume that the atmosphere at rest is isothermal $\left[T_{0}(z)=T_{r}=285 \mathrm{~K}\right]$, which results in a mean density $\rho_{0}(z)=\rho_{r} \exp (-z / H)$, where $H=R T_{r} / g=8340 \mathrm{~m}$ and $\rho_{r}=1.24 \mathrm{~kg} \mathrm{~m}^{-3}$, and $\theta_{0}(z)=T_{r} e^{2 z / 7 H}$. From these parameters, it follows that the Brünt-Väisälä frequency $N=1.83 \times 10^{-2} \mathrm{~s}^{-1}$. This value is quite large compared to standard tropospheric values, but we have found that in our composites the characteristic values for $N$ are around $N=1.5 \times 10^{-2} \mathrm{~s}^{-1}$ between the surface and $500 \mathrm{hPa}$ (not shown). This value is not too far from the isothermal value considered in the model.

To define the topography, we use the NCEP-NCAR topography filtered at truncation T21 and multiplied by a smooth plateau function (see details in the caption of Fig. 8). This smoothing is consistent with the fact that the composite patterns in Figs. 5-7 are dominated by large horizontal scales, with wavelengths around or larger than $20^{\circ}$ in longitude or latitude. To be consistent, we also verified that the EMT series are not much affected by this filtering (see Table 3 ).

The background flow parameters, $u_{r}$ and $\Lambda$ in (9), are adjusted to match the composites of the zonal winds in Fig. 9 along the eastern flank of the massif considered. The values of the wind are taken from the eastern flanks because the cold surges develop there. Note that the zonal wind in the composites of Fig. 9 includes the annual cycle.

\section{b. Evolution of the surface fields and equatorial torques}

For the TP, the low-level wind constant in (9) has been set to $u_{r}=-4 \mathrm{~m} \mathrm{~s}^{-1}$, which gives a low-level background

TABLE 4. Parameters $u_{r}$ and $\Lambda$ used for the model simulations [see (9)], resulting in values of $\hat{T}_{X 1}(t=0)$ compared to $\widetilde{T}_{X 1}(D 0)$, a value of $\hat{T}_{X 2}\left(t=1\right.$ day) simulated with the complete boundary condition (column $\hat{T}_{X 2}$ ), and with the modified boundary condition (20) (column $\hat{T}_{X 2}^{m}$, compared to $\Delta \widetilde{T}_{X 2}$ from the composites in Figs. $4 \mathrm{a}-\mathrm{c}$ ).

\begin{tabular}{lccccccc}
\hline \hline Massif & $u_{r}\left(\mathrm{~m} \mathrm{~s}^{-1}\right)$ & $\Lambda\left(10^{-3} \mathrm{~s}^{-1}\right)$ & $\hat{T}_{X 1}(t=0)(\mathrm{Ha})$ & $\widetilde{T}_{X 1}(D 0)(\mathrm{Ha})$ & $\hat{T}_{X 2}(\mathrm{Ha})$ & $\hat{T}_{X 2}^{m}(\mathrm{Ha})$ & $\Delta \widetilde{T}_{X 2}(\mathrm{Ha})$ \\
\hline Tibet & -4.0 & 5.2 & 63 & 72 & -32.7 & -24.9 & -12.2 \\
Rockies & -5.0 & 3.3 & 29 & 37 & -19.8 & -14.9 & -19.7 \\
Andes & -5.0 & 3.1 & -12 & -16 & 11.6 & 7.3 & 8.7 \\
\hline
\end{tabular}




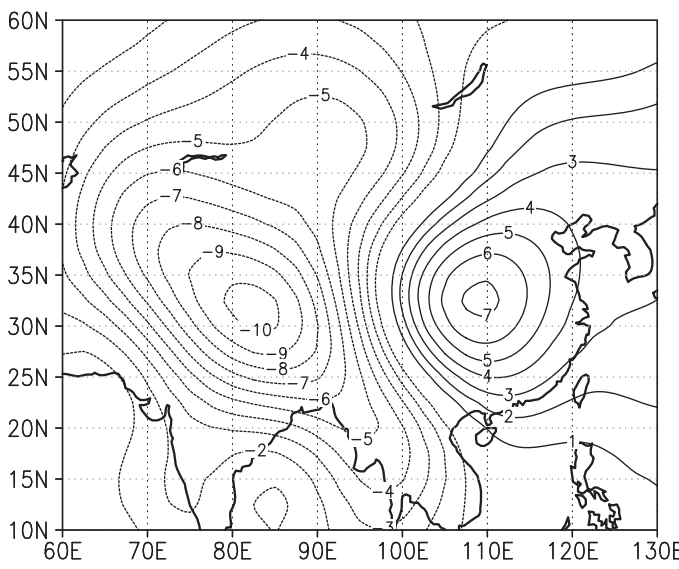

(a)

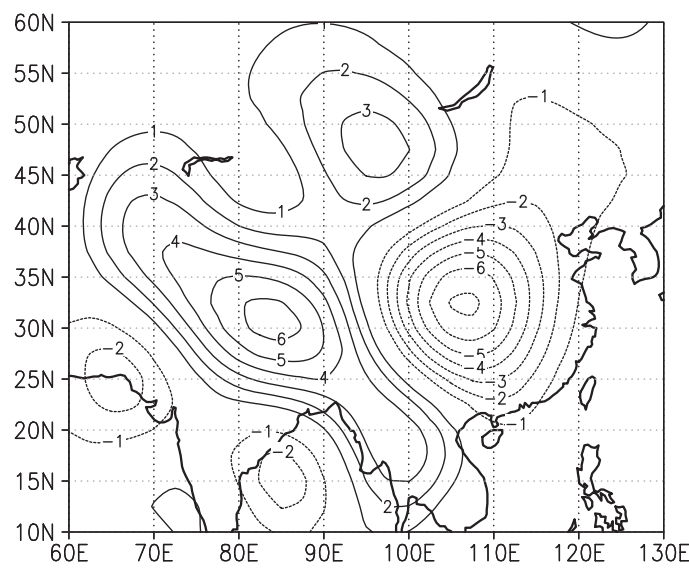

(b)

FIG. 10. (a) Sea level pressure tendency between time $D 0$ and time $D+1$ in the model simulation for the Tibetan Plateau (contours every $1 \mathrm{hPa}$ : zero contour omitted). (b) Surface potential temperature tendency between time $D 0$ and time $D+1$ in the model simulation for the Tibetan Plateau (contours every $1 \mathrm{~K}$ : zero contour omitted).

wind $\bar{u}_{g}\left(\phi_{r}, z=0\right)=-3.46 \mathrm{~m} \mathrm{~s}^{-1}$ at $30^{\circ} \mathrm{N}$. This value is coherent with the composite low-level zonal wind velocities at $30^{\circ} \mathrm{N}$ along the eastern flank of the TP shown in Fig. 9a. Still according to Fig. 9a, we take for the shear parameter $\Lambda=5.2 \times 10^{-3} \mathrm{~s}^{-1}$, so the background zonal wind in the model is around $58 \mathrm{~m} \mathrm{~s}^{-1}$ at $200 \mathrm{hPa}$ and $30^{\circ} \mathrm{N}$. Note also that with the orography in Fig. $8 \mathrm{~b}$, the low-level wind value $u_{r}=-4 \mathrm{~m} \mathrm{~s}^{-1}$ yields an equatorial mountain torque $\widetilde{T}_{\mathrm{TP} 1}=63 \mathrm{Ha}$ in the theoretical model (17a) that compares with the peak composite value of $\widetilde{T}_{\mathrm{TP} 1}$ in Fig. 4a (72 Ha). A similar tuning of the flow parameters using the composites for the Rockies and the Andes in Figs. 9b,c leads to $u_{r}=-5 \mathrm{~m} \mathrm{~s}^{-1}$ for both and $\Lambda=3.3 \times 10^{-3} \mathrm{~s}^{-1}$ for the Rockies and $\Lambda=3.1 \times$ $10^{-3} \mathrm{~s}^{-1}$ for the Andes. From these setups it follows that $\widetilde{T}_{\mathrm{R} 1}=29 \mathrm{Ha}$ and $\widetilde{T}_{\mathrm{Ad} 1}=-12 \mathrm{Ha}$, again values that compare reasonably well with those in the composites at $D 0$ and which are around 37 and $-16 \mathrm{Ha}$, respectively (see also Table 4 where all these results are summarized).

Figure 10 shows the disturbance surface pressure and surface temperature in the theoretical model after 1 day of integration for the TP. The choice of this 1-day interval here and for the other mountains is motivated by the fact that, in the composites, the anomalies on the eastern flanks of the mountains develop on such a time scale (Figs. 4a-c). On the eastern flank of the TP, the model predicts a rise in surface pressure of about $7 \mathrm{hPa}$ and a drop in surface temperature of about $7 \mathrm{~K}$ (Fig. 10), both centered around $30^{\circ}-35^{\circ} \mathrm{N}, 105^{\circ}-110^{\circ} \mathrm{E}$, that are reminiscent of the structure obtained in the composite at lag $D+2$ in Figs. 5e,f. However, to the west of the longitude $\lambda=95^{\circ} \mathrm{E}$ the linear model predicts a drop in surface pressure and a rise in surface temperature, which are absent from the composites.
For the Rockies and the Andes the results from the model have the same level of realism when compared to their corresponding composites (not shown): the model predicts a realistic large-scale pressure increase and a largescale temperature decrease to the east of the mountains, as well as changes of the opposite sign to the west of the mountains.

From the surface pressure pattern in Fig. 10, and coming back for instance to the schematic picture in Fig. 1, it is clear that the interaction between the TP and the flow at that time yields a negative torque along the second equatorial axis. If we evaluate it from the model by using (1b) we find that $\hat{T}_{\mathrm{TP} 2}(t=1 \mathrm{~d})=-32 \mathrm{Ha}$ and is largely superior in amplitude when compared to the fastest change in $\widetilde{T}_{\mathrm{TP} 2}$ that occurs in one day in the composite $\left[\Delta \tilde{T}_{\mathrm{TP} 2}=\tilde{T}_{\mathrm{TP} 2}(D+1)-\tilde{T}_{\mathrm{TP} 2}(D 0)=-12 \mathrm{Ha}\right.$ in Fig. 4$]$. For the Andes and the Rockies, the discrepancy is not as pronounced (see Table 4), providing we take into account that in these two regions the cold surges have started to develop around $D-1$. This is clearly apparent for the composite of surface temperature at $D 0$ in Figs. $6 \mathrm{~d}$ and $7 \mathrm{~d}$. As a result, and for these two massifs, the largest 1-day change in $\tilde{T}_{2 X}$ is between $D-1$ and $D 0$ (see Fig. 4). For the Rockies the model predicts a torque $\hat{T}_{\mathrm{R} 2}=-19.8 \mathrm{Ha}$ that corresponds to $\Delta \tilde{T}_{\mathrm{R} 2}=\tilde{T}_{\mathrm{R} 2}(\mathrm{D} 0)-\tilde{T}_{\mathrm{R} 2}(\mathrm{D}-1)=$ $-19.7 \mathrm{Ha}$. For the Andes, as for the TP, the torque is overestimated: $\hat{T}_{\mathrm{Ad} 2}=11.6 \mathrm{Ha}$ whereas $\Delta \tilde{T}_{\mathrm{Ad} 2}=$ $\tilde{T}_{\mathrm{Ad} 2}(\mathrm{D} 0)-\tilde{T}_{\mathrm{Ad} 2}(\mathrm{D}-1)=8.7 \mathrm{Ha}$.

\section{c. Results with a modified lower boundary condition}

The unrealistic surface responses that occur in the model to the west of the massifs considered are due to (i) the linear boundary condition in (12), (ii) the positive 


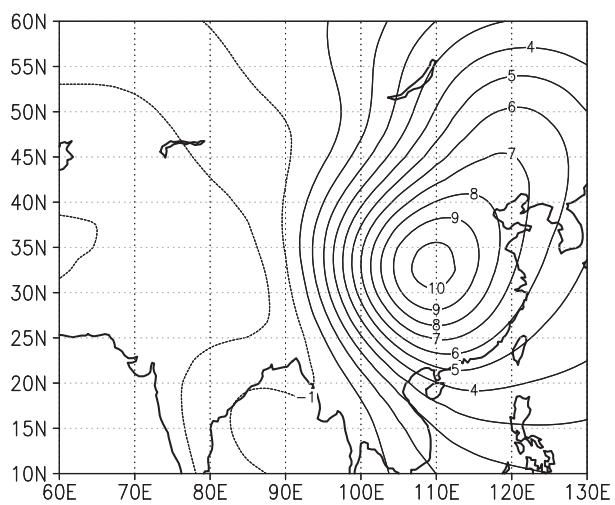

(a)

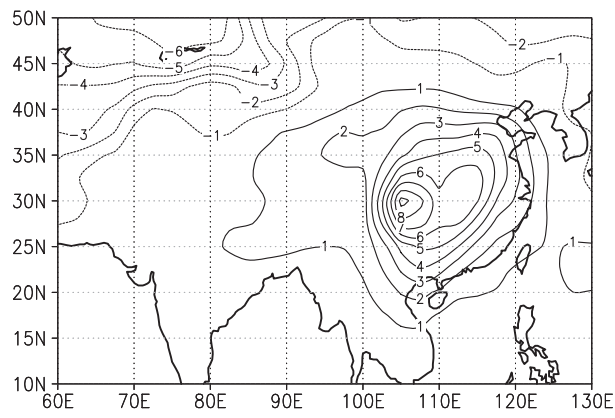

(c)

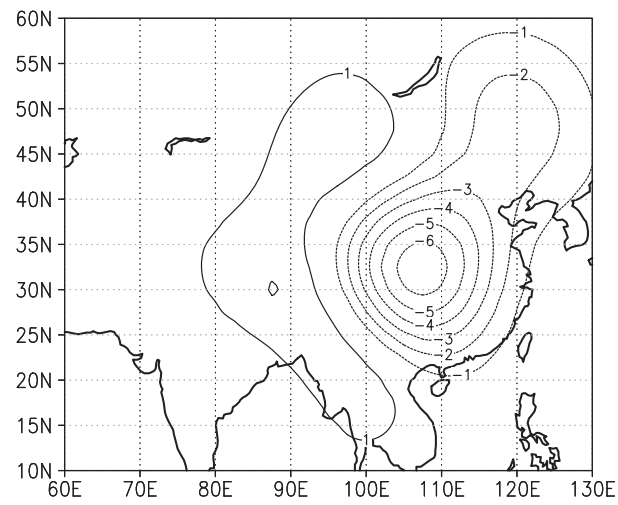

(b)

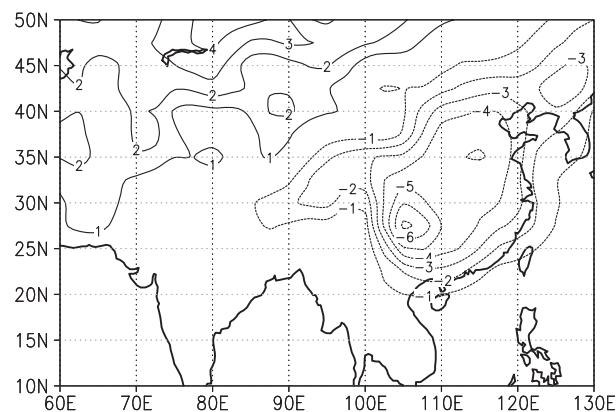

(d)

FIG. 11. (a),(b) As in Fig. 10 but with the modified boundary condition: (c) Tendency of $\widetilde{P}_{S}$ between lag $D 0$ and $D+1$ in the composite keyed on the 20 strongest events on $\widetilde{T}_{\mathrm{TP} 1}$ (contours every $1 \mathrm{hPa}$; zero contour omitted). (d) Tendency of $\widetilde{T}_{50 \mathrm{~m}}$ between lag $D 0$ and $D+1$ in the composite keyed on the 20 strongest events on $T_{\mathrm{TP} 1}$ (contours every $1 \mathrm{~K}$ : zero contour omitted).

mountain slope $\partial_{\lambda} h$ west of the mountain crests, and (iii) the zonally uniform low-level wind $\bar{u}_{g}(z=0)$. In reality, however, the region west of the crests of the mountains corresponds either to very high altitudes, where the surface wind is essentially positive according to the zonal wind composite in Fig. 9, or to more moderate altitudes, where the zonal wind composite is almost null near the ground (see again Fig. 9). These effects can be accounted

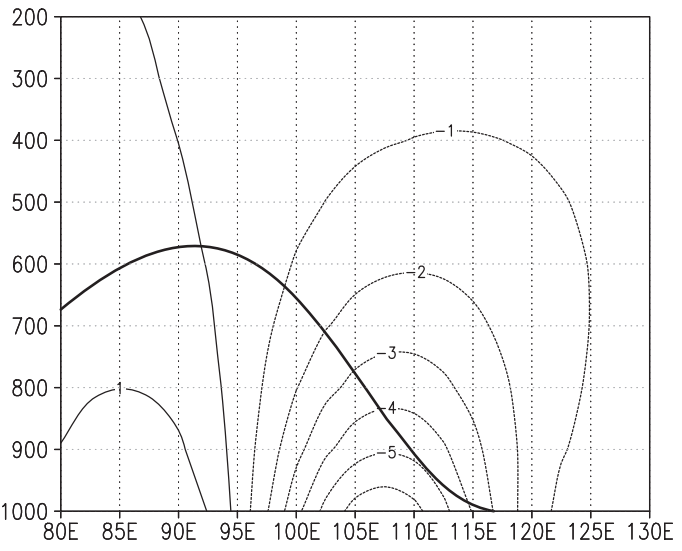

(a)

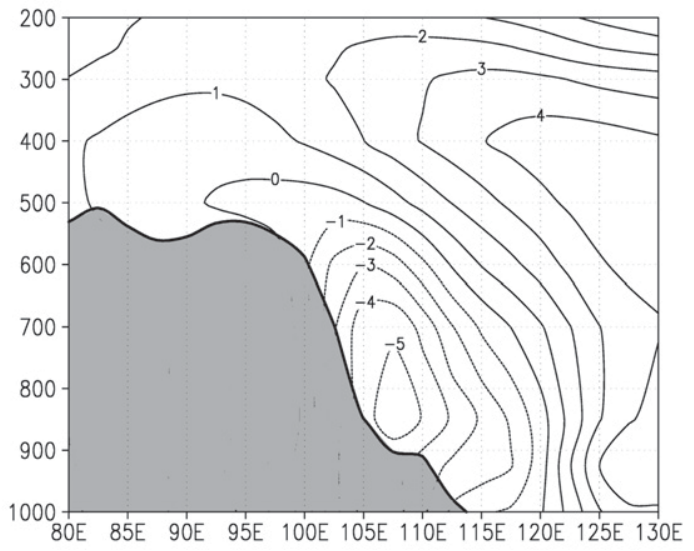

(b)

FIG. 12. (a) Air temperature anomaly (K, thin contours) at $32.5^{\circ} \mathrm{N}$ at time $D+1$ in the model simulation. The thick black line represents the model ground elevation. (b) Composite of air temperature anomaly (relative to the climatology) 1 day after the 20 strongest peaks in $\widetilde{T}_{\mathrm{TP} 1}$. 


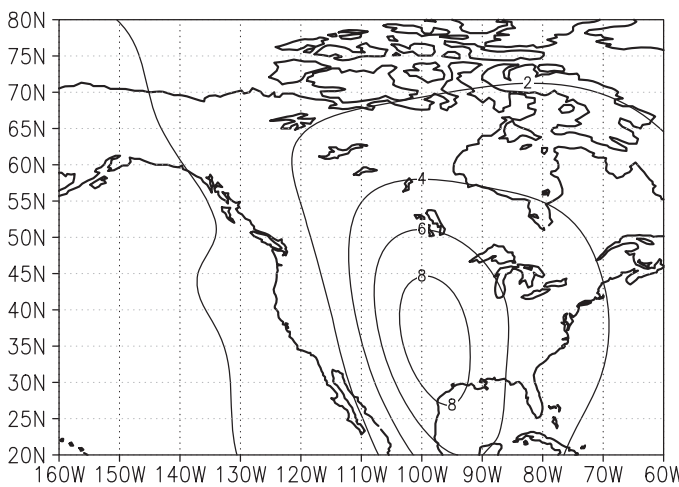

(a)

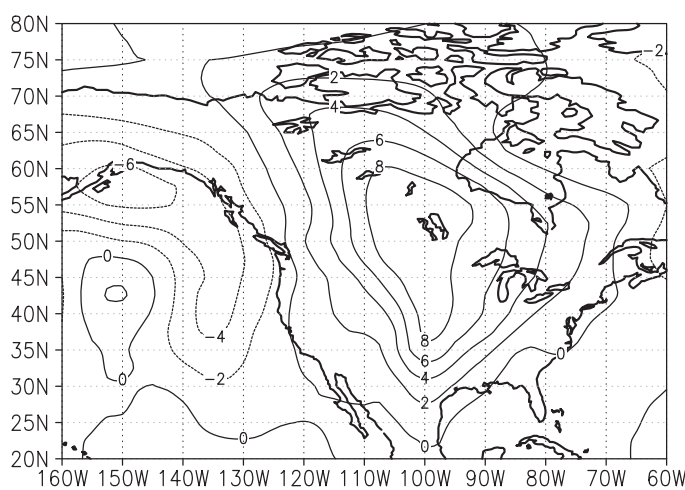

(c)

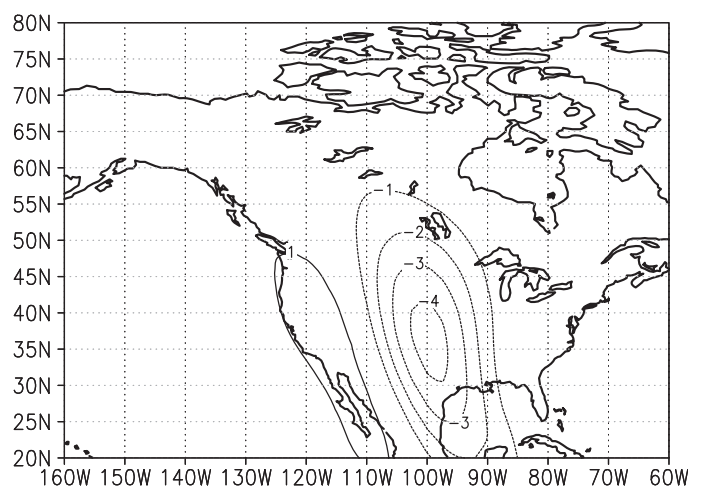

(b)

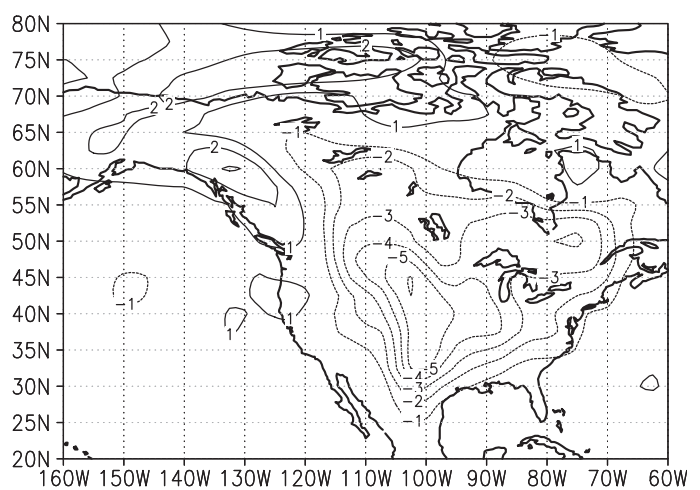

(d)

FIG. 13. As in Fig. 11 but for the Rockies. The 1-day differences in (c) and (d) are between the composites at $D 0$ and $D-1$.

for in the second bracket of (7) by imposing $w^{\prime}=0$ and $F^{\prime}$ as in (18), but taking $Q^{\prime}$ such that (12) becomes

$$
\left(\partial_{t}+\frac{u_{r}}{a} \partial_{\lambda}\right) \Phi_{z}^{\prime}-\frac{\Lambda}{a} \frac{\partial \Phi^{\prime}}{\partial \lambda}=-\frac{N^{2} u_{r}}{a} \min \left(\frac{\partial h}{\partial \lambda}, 0\right)
$$

This correction annihilates the forcing when the slopes are positive but does not modify $\hat{T}_{X 1}(t=0)$ since $F^{\prime}$ is not changed and $Q^{\prime}$ does not enter into the momentum equation. This term counteracts the fact that the linear boundary condition (12) is unrealistic over the western slopes of the mountains (Fig. 10). From now on, the boundary condition (20) will be called the modified boundary condition.

For the TP, the surface patterns obtained in this case (Figs. 11a,b) are much closer to the composites, essentially because the model response is now almost null to the west of $95^{\circ} \mathrm{E}$. To make the comparison between the model at day 1 and the evolution in the composites even more precise, Figs. $11 \mathrm{c}$ and $11 \mathrm{~d}$ show the difference in the composite fields between $D+1$ and $D 0$. This comparison shows that the rise in surface pressure of $\sim 10 \mathrm{hPa}$ and the drop in surface temperature of $\sim 6 \mathrm{~K}$ predicted by the model (Figs. 11a,b) correspond quite well to the variations during the first day in the composite, which are around $9 \mathrm{hPa}$ and $7 \mathrm{~K}$ (Figs. 11c,d). Note that in the composite the maximum in surface pressure and the minimum in surface temperature are slightly to the west and south of the ones predicted by the model. However, the extension of the surface temperature signal as predicted by the model corresponds quite well with the composite.

Another interesting property of the model is that it predicts a dome of cold air trapped in the lower half of the troposphere over the eastern slopes of the mountains (Fig. 12a). This vertical structure is also found in the zonal vertical section from the composite in Fig. $12 \mathrm{~b}$. In this sense the model reproduces the well-known vertical structure of the temperature signals associated with cold surges (e.g., Garreaud 2001, and references therein).

For the Rockies, Fig. 13 shows that the model has some skill in reproducing the initial development of the cold surges as observed in the composites. It predicts 


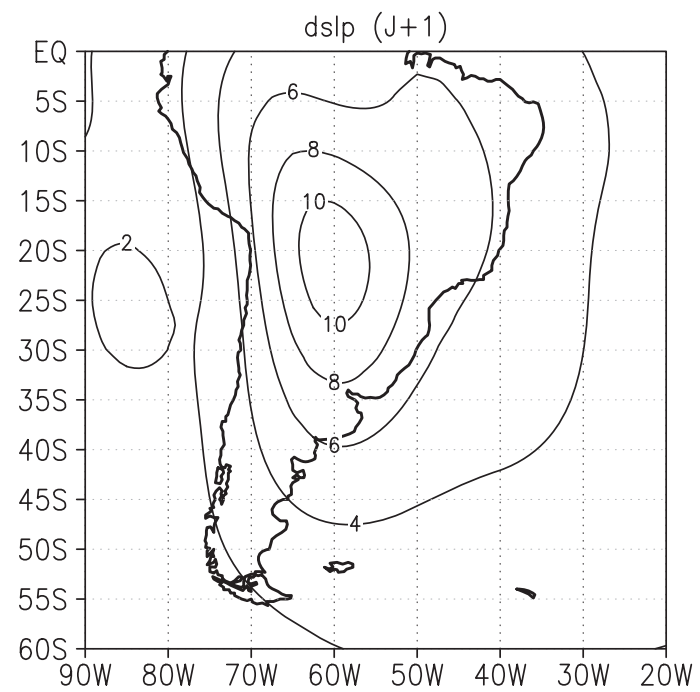

(a)

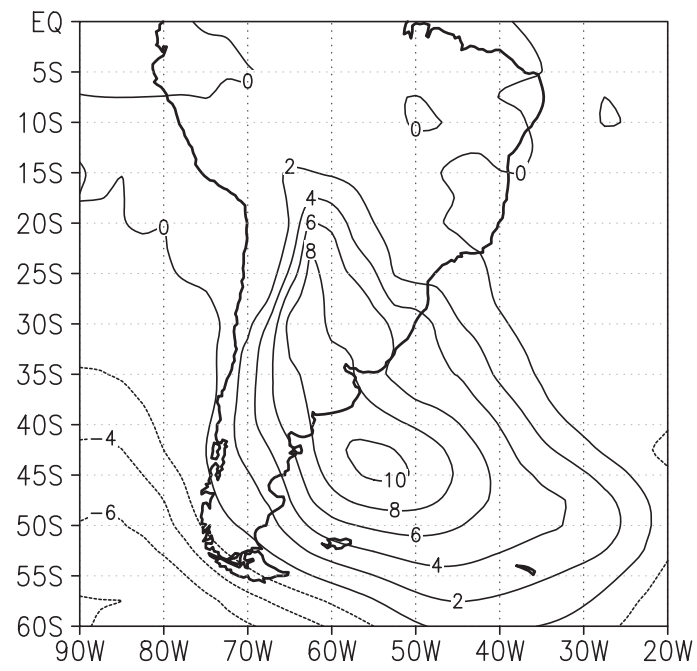

(c)

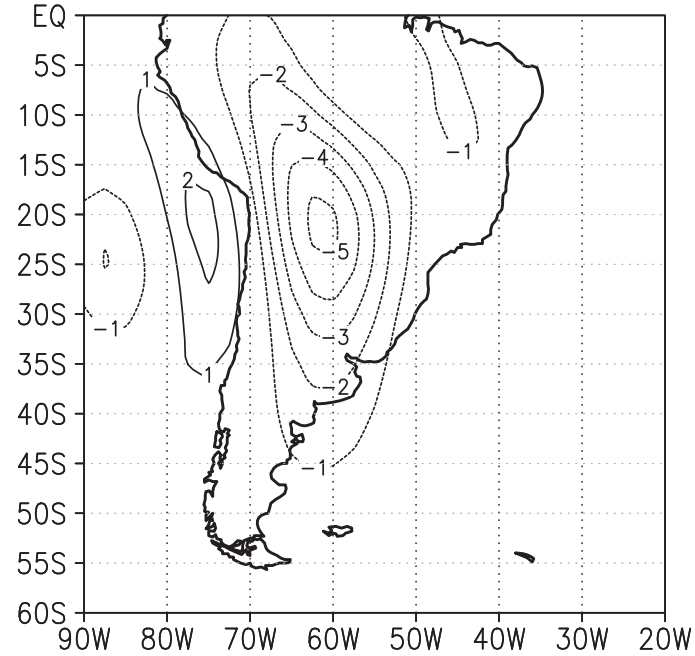

(b)

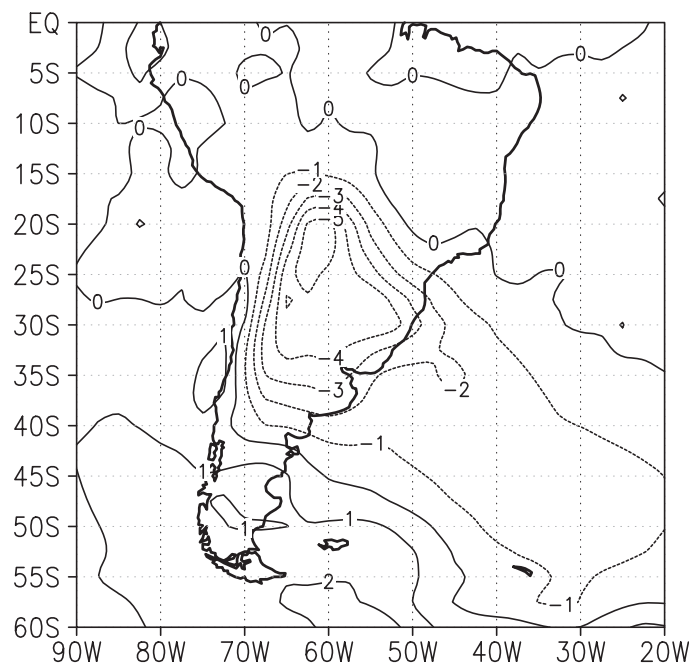

(d)

FIG. 14. As in Fig. 13 but for the Andes.

a temperature drop of $6 \mathrm{~K}$ (Fig. 13b), which only slightly exceeds the largest 1-day tendency from the composites in Fig. 13d. The prediction of the location of the temperature signal is also quite good, and the model predicts a rise of $8 \mathrm{hPa}$ in the surface pressure (Fig. 13a), which compares with the value observed in the composite (9 hPa, see Fig. 13c). Accordingly, the signal on the second EMT component $\left[\hat{T}_{\mathrm{R} 2}(t=1\right.$ day $\left.)=-14.9 \mathrm{Ha}\right]$ compares well with the largest 1-day $\widetilde{T}_{\mathrm{R} 2}$ tendency in the composite $\left(\Delta \widetilde{T}_{\mathrm{R} 2}=-19.7 \mathrm{Ha}\right.$, see also Fig. $4 \mathrm{~b}$ and Table 4).

For the Andes, the model predicts a 1-day temperature drop up to $5 \mathrm{~K}$ in one day east of the Andes (Fig. 14b), which is also the value given by the composite in Fig. 14d, the location of this temperature anomaly being well reproduced. For the surface pressure, the model (Fig. 14a) only captures a part of the signal observed in the corresponding composite (Fig. 14c), namely the part of the signal confined to the eastern flank of the mountains. There, the surface pressure increase in the model is near $10 \mathrm{hPa}$ (Fig. 14a), whereas it is $8 \mathrm{hPa}$ in the composite (Fig. 14c). These last correspondences explain that the second EMT signal from the model $\left[\hat{T}_{\mathrm{Ad} 2}(1\right.$ day $)=$ $7.3 \mathrm{Ha}$ ] compares well with the largest 1-day tendency in the composites $\left(\Delta \widetilde{T}_{\mathrm{Ad} 2}=8.7 \mathrm{Ha}\right.$; see also Fig. $4 \mathrm{c}$ and Table 4). The vertical structure of the cold dome from the model (not shown) is also similar to Fig. 7 from Garreaud (2000), which shows the meridional and vertical extension 
of the cold domes associated with the South American cold surges.

\section{Summary and discussion}

The two components of the EMT associated with three major mountain massifs (the TP, the Rockies, and the Andes) have been analyzed in the NCEP reanalysis data. When the first equatorial axis is placed $90^{\circ}$ to the west of the massif and the second equatorial axis at the longitude of the center of mass of the massif, the strong signals on $\widetilde{T}_{X 1}$ are followed one or two days later by strong signals of the opposite sign on $\widetilde{T}_{X 2}$ (Figs. 3 and 4). These regional contributions partly explain why the global EMT vector rotates westward in the equatorial plane (Fig. 2). Their contributions can add up constructively to the contribution of Antarctica, which is the major single contributor to the global equatorial torque, and whose equatorial torque also rotates westward (Fig. 3d).

Returning to the TP and the Rockies, the composites of the surface pressure fields in Figs. 5 and 6 respectively show that a positive signal in $\widetilde{T}_{X 1}$ is, in general, associated with anomalies in surface pressure located poleward of the massif considered. As time evolves, these anomalies shift along the eastern flank of the massif considered, which explains the negative signal on $\widetilde{T}_{X 2}$. This characteristic evolution of the surface pressure also occurs around the Andes (Fig. 7), provided the sign of the equatorial torques is inverted (because the Andes are located in the Southern Hemisphere). Interestingly, the evolution of the surface temperature and surface pressure east of these three massifs is very pronounced and strongly reminiscent of what occurs during the cold surges that severely affect the weather to their eastern side.

From these observational results, we make two hypotheses: (i) the equatorial mountain torques measure the dynamical forcing of the cold surges by the mountains and (ii) this dynamical forcing is a substantial driver of the cold surges.

To support these two hypotheses, we develop a mechanistic model for the cold surges that only contains the basic ingredients needed to explain the above observations. For this purpose, we follow Smith (1984) and adapt the quasigeostrophic $f$-plane Eady (1949) model for baroclinic flow by introducing a mountain forcing via a freeslip lower boundary condition and by formulating this model on a sphere. It is then shown that, in this framework, the free-slip boundary condition is locally strictly equivalent to a lateral force (i.e., a force perpendicular to the surface wind) and that the amplitude of this lateral force, given in (18), is consistent with the mountain "lift" forces given in Smith (1979). When the low-level background flow is easterly, this lift force results in a positive mountain torque $\hat{T}_{X 1}$ (in the Northern Hemisphere) comparable to the one observed.

If we impose that at $t=0$ the disturbance field is null in this model, high pressure and low temperature anomalies develop in one day along the eastern flank of the massif. When the low-level wind and the upper-level shear correspond to the values observed at $D 0$ in the composites keyed on the peaks in $\widetilde{T}_{X 1}$, the 1-day tendencies of the model responses in pressure and temperature are compatible with the ones observed in the composites of the reanalysis data immediately after the peaks in $\widetilde{T}_{X 1}$ (Figs. 11,13 , and 14). Note that from the surface pressure anomalies predicted by this mechanistic model we can evaluate a tendency on the torque along the second axis $\hat{T}_{X 2}$, which is also comparable in amplitude to the one observed (see Table 4). Note nevertheless that, like many other theoretical models for orographic flows (e.g., that of Smith 1984), our model simplifies considerably the basic setup and initial conditions. It is used here mainly to show that mountain forces translating in EMTs that are about the amplitude found in reality are strong enough to initiate cold surges. A more realistic treatment of the synoptic systems that yields to the peaks in $\widetilde{T}_{X 1}$ (i.e., the initial condition in the model) would certainly improve our dynamical understanding of the life cycle of the cold surges.

Since our results suggest that the existence of poleward mountain forces yields to cold surges in a linear baroclinic context, it needs to be put in perspective with the other explanations for cold surges that have been proposed in the past. In many aspects they actually complement them. Some theories attribute the clockwise displacement of cold surges to topographic Rossby or Kelvin waves (e.g., Hsu 1987; Compo et al. 1999, and references therein). Other theories attribute the equatorward propagation of the cold surges to nonlinear processes where the cold advection by the meridional wind is the main contributor. This interpretation is in good part supported by model and diagnostic studies (e.g., Sumi 1983; Colle and Mass 1995; Garreaud 2000). All of these theories for the cold surge propagation require the presence of a preexisting inversion near or below the mountain top and do not take into account the background flow.

However, Reason (1994) has suggested that linear mechanisms and the effect of the background flow are important to provide a large-scale preconditioning of the cold surges, at least over the Andes and TP. Our model, by taking into account the interaction of the large-scale background flow with the orography, follows this line of work. It explains how the mountain forcing can trigger the initial development of a cold surge by building up rapidly the dome of cold air in which low-level orographically trapped subsynoptic disturbances can subsequently develop (Fig. 12a). 
In past studies about the equatorial AAM budget, it has been shown that the evolution of the EAAM is largely dominated by the equivalent barotropic planetary waves with zonal wavenumber $s=1$, and that the mountain torque has a rather small impact on these waves. On the contrary, the evolution of the mass term plays an important role in the EAAM evolution associated with planetary barotropic waves (Egger and Hoinka 2002; Feldstein 2006). In the present study, the focus is on regional scales, so we do not try to address this problem. The model used is, in fact, not adapted to this purpose since it is based on the anelastic approximation, which filters out the equivalent barotropic waves and has an AAM budget that does not contain mass terms (not shown). Another reason for not trying to address the response of the EAAM to the equatorial torques is that the EAAM budget is not well closed in the reanalysis data. It is thus extremely difficult to establish where the EAAM anomalies produced by regional EMTs are in fact redistributed. Even though our model results are only indicative in this respect, the anticyclonic patterns developing eastward of the mountains and produced by a positive $\hat{T}_{X 1}$ in our model are likely to give a negative $M_{2}$ and a small $M_{1}$. This picture hides the fact that in reality barotropic waves rapidly redistribute the EAAM over the globe, making it difficult to identify the impact of regional torques on the global EAAM.

From a practical viewpoint, these results address the significance of mountain-induced lateral (or lift) forces for the regional weather and they indicate that one should diagnose the equatorial components of the mountain torque and not only its axial component (as done in Brown 2004 or Lott et al. 2005). In GCMs, there are essentially two ways to modify these lift forces. One is very efficient and consists in modifying the elevation of the explicit model orography [yielding to the envelope orography in Wallace et al. (1983)]. However, this solution is not completely satisfactory since it increases the number of places that are below the ground in models. An alternative solution consists in parameterizing them as done here with our term $F^{\prime}$ in (18) but distributing it over a finite depth. This depth could be the depth of the valleys in which we consider that the large-scale flow does not enter, to follow the arguments in Wallace et al. (1983) [see also Eq. (5) in Lott 1999]. The fact that this term $F^{\prime}$ can be significant for the synoptic weather in key regions of the climate system stresses its potential significance for coupled climate models. To illustrate this importance, the study of Kitoh (2004) is very instructive. It shows that in a state-of-the-art coupled model, the simulation of monsoon precipitations is very sensitive to the large-scale mountain elevation. As support that these issues may well be important for monsoon prediction, recall here that
Mailler and Lott (2009) found that the signals on the equatorial mountain torques due to the Tibetan Plateau are followed by increased winter monsoon precipitation.

Acknowledgments. The NCEP reanalysis data was kindly provided by the NOAA/OAR/ESRL PSD, Boulder, Colorado, from their Web site at http://www.cdc. noaa.gov/.

\section{REFERENCES}

Bessemoulin, P., P. Bougeault, A. Genoves, A. J. Clar, and D. Puech, 1993: Mountain pressure drag during PYREX. Beitr. Phys. Atmos., 66, 305-325.

Bretherton, F. P., 1966: Critical layer instability in baroclinic flows. Quart. J. Roy. Meteor. Soc., 92, 325-334.

Brown, A. R., 2004: Resolution dependence of orographic torques. Quart. J. Roy. Meteor. Soc., 130, 3029-3046.

Buzzi, A., and S. Tibaldi, 1978: Cyclogenesis in the lee of the Alps: A case study. Quart. J. Roy. Meteor. Soc., 104, 271-287.

Chang, C.-P., and K. M. Lau, 1980: Northeasterly cold surges and near-equatorial disturbances over the winter MONEX area during December 1974. Part II: Planetary-scale aspects. Mon. Wea. Rev., 108, 298-312.

_ J. E. Erickson, and K. M. Lau, 1979: Northeasterly cold surges and near-equatorial disturbances over the winter MONEX area during December 1974. Part I: Synoptic aspects. Mon. Wea. Rev., 107, 812-829.

Chen, T.-C., W.-R. Huang, and J.-H. Yoon, 2004: Interannual variation of the East Asian cold surge activity. J. Climate, 17, 401-413.

Clark, J. H. E., 1990: An observational and theoretical study of Colorado lee cyclogenesis. J. Atmos. Sci., 47, 1541-1561.

Colle, B. A., and C. Mass, 1995: The structure evolution of cold surges east of the Rocky Mountains. Mon. Wea. Rev., 123, 2577-2610.

Compo, G. P., G. N. Kiladis, and P. J. Webster, 1999: The horizontal and vertical structure of East Asian winter monsoon pressure surges. Quart. J. Roy. Meteor. Soc., 125, 29-54.

Davies, H. C., and P. D. Phillips, 1985: Mountain drag along the Gotthard section during ALPEX. J. Atmos. Sci., 42, 20932109.

Eady, E. T., 1949: Long waves and cyclone waves. Tellus, 1, 33-52.

Egger, J., 1988: Alpine lee cyclogenesis: Verification of theories. J. Atmos. Sci., 45, 2187-2203.

— , and K.-P. Hoinka, 2000: Mountain torques and the equatorial components of global angular momentum. J. Atmos. Sci., 57, 2319-2331.

— angular momentum: Covariance functions. Quart. J. Roy. Meteor. Soc., 128, 1137-1157.

- , and - 2008: Mountain torque events at the Tibetan Plateau. Mon. Wea. Rev., 136, 389-404.

_- K. Weickmann, and K.-P. Hoinka, 2007: Angular momentum in the global atmospheric circulation. Rev. Geophys., 45, RG4007, doi:10.1029/2006RG000213.

Feldstein, S. B., 2006: Dynamical processes of equatorial atmospheric angular momentum. J. Atmos. Sci., 63, 565-581.

Garreaud, R. D., 2000: Cold air incursions over subtropical South America: Mean structure and dynamics. Mon. Wea. Rev., 128, 2544-2559. 
— 2001: Subtropical cold surges: Regional aspects and global distribution. Int. J. Climatol., 21, 1181-1197.

Hsu, H.-H., 1987: Propagation of low-level circulation features in the vicinity of mountain ranges. Mon. Wea. Rev., 115, 1864-1893.

— teleconnection patterns. J. Atmos. Sci., 42, 1693-1710.

Iskenderian, H., and D. A. Salstein, 1998: Regional sources of mountain torque variability and high-frequency fluctuations in atmospheric angular momentum. Mon. Wea. Rev., 126, 1681-1694.

Kalnay, E., and Coauthors, 1996: The NCEP/NCAR 40-Year Reanalysis Project. Bull. Amer. Meteor. Soc., 77, 437-471.

Kitoh, A., 2004: Effects of mountain uplift on East Asian summer climate investigated by a coupled atmosphere-ocean GCM. J. Climate, 17, 783-802.

Lott, F., 1999: Alleviation of stationary biases through a mountain drag parameterization scheme and a simple representation of mountain lift forces. Mon. Wea. Rev., 127, 788-801.

—_, and F. d'Andrea, 2005: Mass and wind axial angular momentum responses to mountain torques in the 1-25-day band. Links with the Arctic Oscillation. Quart. J. Roy. Meteor. Soc., 131, 1483-1500, doi:10.1256/qj.03.168.

_ A. W. Robertson, and M. Ghil, 2004: Mountain torques and Northern Hemisphere low-frequency variability. Part I: Hemispheric aspects. J. Atmos. Sci., 61, 1259-1271.

- L. Loudard, and A. Martin, 2005: Links between the mountain torque and the Arctic Oscillation in the Laboratoire de Météorologie dynamique (LMDz) general circulation model. J. Geophys. Res., 110, D22107, doi:10.1029/ 2005JD006073.

Mailler, S., and F. Lott, 2009: Dynamical influence of the Tibetan Plateau on the winter monsoon over southeastern Asia. Geophys. Res. Lett., 36, L06708, doi:10.1029/2008GL036952.

Marengo, J., A. Cornejo, P. Satyamurty, and C. Nobre, 1997: Cold surges in tropical and extratropical South America: The strong event in June 1994. Mon. Wea. Rev., 125, 2759-2786.

Pierrehumbert, R. T., 1985: A theoretical model of orographically modified cyclogenesis. J. Atmos. Sci., 42, 1244-1258.

Reason, C. J. C., 1994: Orographically trapped disturbances in the lower atmosphere: Scale analysis and simple models. Meteor. Atmos. Phys., 53, 131-136.
Rosen, R. D., and D. A. Salstein, 1983: Variations in atmospheric angular momentum on global and regional scales and the length of day. J. Geophys. Res., 88, 5451-5470.

Schultz, D. M., W. E. Bracken, L. F. Bosart, G. J. Hakim, M. A. Bedrick, M. J. Dickinson, and K. R. Tyle, 1997: The 1993 superstorm cold surge: Frontal structure, gap flow, and tropical impact. Mon. Wea. Rev., 125, 5-39.

Seluchi, M. E., and J. T. Nery, 1992: Condiciones meteorológicas asociadas a la ocurrencia de heladas en la región de Maringá. Rev. Bras. Meteor., 7, 523-534.

Slingo, J. M., 1998: Extratropical forcing of tropical convection in a northern winter simulation with the UGAMP GCM. Quart. J. Roy. Meteor. Soc., 124, 27-51.

Smith, R. B., 1979: Some aspects of the quasi-geostrophic flow over mountains. J. Atmos. Sci., 36, 2385-2392.

_ 1984: A theory of lee cyclogenesis. J. Atmos. Sci., 41, 1159-1168. , 1986: Further development of a theory of lee cyclogenesis. J. Atmos. Sci., 43, 1582-1602.

Speranza, A., A. Buzzi, A. Trevisan, and P. Malguzzi, 1985: A theory of deep cyclogenesis in the lee of the Alps. Part I: Modifications of baroclinic instability by localized topography. J. Atmos. Sci., 42, 1521-1535.

Sumi, A., 1983: A study on cold surges around the Tibetan Plateau by using numerical models. J. Meteor. Soc. Japan, 63, 377-396.

Tangang, F. T., L. Juneng, E. Salimun, P. N. Vinayachandran, Y. K. Seng, C. J. C. Reason, S. K. Behera, and T. Yasunari, 2008: On the roles of the northeast cold surge, the Borneo vortex, the Madden-Julian Oscillation, and the Indian Ocean Dipole during the extreme 2006/2007 flood in southern peninsular Malaysia. Geophys. Res. Lett., 35, L14S07, doi:10.1029/ 2008 GL033429.

Wallace, J. M., S. Tibaldi, and A. J. Simmons, 1983: Reduction of systematic forecast errors in the ECMWF model through the introduction of an envelope orography. Quart. J. Roy. Meteor. Soc., 109, 683-717.

Weickmann, K. M., and P. D. Sardeshmukh, 1994: The atmospheric angular momentum cycle associated with the Madden-Julian oscillation. J. Atmos. Sci., 51, 3194-3208.

Zhang, Y., K. R. Sperber, and J. S. Boyle, 1997: Climatology and interannual variation of the East Asian winter monsoon: Results from the 1979-95 NCEP/NCAR reanalysis. Mon. Wea. Rev., 125, 2605-2619. 